\title{
Gut and Colony Microbiota of Honey Bees Apis mellifera: Social Immunity, Opportunistic Disease and Survival Overwinter.
}

Kirk E. Anderson ( $\sim$ kirk.anderson@ars.usda.gov )

"USDA-ARS Bee Research Center" https://orcid.org/0000-0002-9846-2603

\section{Patrick Maes}

University of Arizona Department of Entomology and Insect Science

\section{Research}

Keywords: Microbiome, Hygiene, disease, climate, gut dysbiosis, gut bacteria, hive bacteria, mouthparts, midgut, disease suppression, opportunistic disease

Posted Date: August 9th, 2021

DOl: https://doi.org/10.21203/rs.3.rs-757584/v1

License: (c) This work is licensed under a Creative Commons Attribution 4.0 International License.

Read Full License 


\section{Abstract}

\section{Background}

Overwintering is a major contributor to honey bee colony loss and involves changes in environmental conditions, host physiology and group behavior that influence disease susceptibility. Honey bees possess a secretory head gland that interfaces with the extended colony environment on many levels, producing pro-oxidants, antioxidants and antimicrobial peptides. With the coming of winter, colonies produce a longlived (diutinus) worker phenotype that survives until environmental conditions improve. We used a known-age worker cohort to investigate microbiome integrity and social gene expression of diutinus workers overwinter. We provide additional context by contrasting host-microbial interactions from warm outdoor and cold indoor overwintering environments.

Results

We produce the first evidence that social immune gene expression is associated with the core hindgut and colony microbiota in honey bees, and highlight the midgut as a target of opportunistic disease overwinter. We discovered a distinct physiological and microbiological trajectory for diutinus workers that differs drastically from younger, short-lived workers in the colony. Diutinus bees were associated with decreased fungal load and decreased bacterial diversity, and increased core microbiota and longevity. Colonies overwintered indoors maintained a stable or improved microbiota structure and complimentary gene expression overwinter. In contrast, workers from colonies overwintered outdoors in warm southern conditions possessed changes co-occurring throughout the alimentary tract microbiota that suggest opportunistic disease progression and resistance in diutinus workers, but susceptibility to opportunistic disease in younger workers that emerged during the winter, including increases in Enterobacteriaceae, fungal load and bacterial diversity abundance.

\section{Conclusions}

Our results highlight social selection pressures that shaped the colony and hindgut microbiome with evolution to a perennial life history. The results are consistent with a "group level" explanation of social immunity, including host associations with the colony microbiota, and a social immune response by longlived diutinus workers to accompany microbial opportunism. The cost/benefit ratio associated with limited expression of the diutinus phenotype may be a strong determinant of colony survival overwinter. The relationship of colony and gut microbiota with social immune function highlights the range of hostmicrobial interaction associated with the honey bee superorganism, and its potential influence on colony health, disease resistance and gut integrity.

\section{Background}

Social insects are under strong selection to evolve antibiotic mechanisms that result in group hygiene, or social immunity $[1,2]$. There are fascinating social insect symbioses evolved to control the abundance of 
particular microbial species throughout the nest, hive or social environment [3-6]. The social context of disease susceptibility involves multiple factors that shape the evolution of life history, including resident microbial symbionts and resistance to opportunistic disease [7-10]. Many opportunistic disease states are associated with changes in core hindgut structure or extended "colony" microbiota overgrowth, highlighting the importance of microbiome integrity or taxonomic membership in disease susceptibility. How, when and where opportunistic pathogens can invade the host depends in part on their ability to occupy sub-optimal or fringe niches with consistent host exposure, to form relationships with, or outcompete other resident microbes, and to evade host defenses $[8,11,12]$. The primary function of the eukaryotic microbiome is protection from pathogens, and many factors may weaken the core microbiota rendering the host organism susceptible to disease [12-16]. In humans, the skin and nasal pharyngeal microbiome are considered the first line of defense against pathogen colonization and infection [17]. Analogous to these protective human niches, the honey bee is host to a variety of microbiotas associated with a type of "social skin" that occurs throughout the colony and hive $[4,13,14,18,19]$. This social or colony microbiota is associated with nutrient processing and information sharing including the structurally complex worker mouthparts that perform these tasks and a secretory hypopharyngeal gland (HPG) in the worker head. The HPG produces a highly nutritious and bioactive jelly substance containing pro-oxidants, antioxidants and antimicrobial peptides that interface constantly with the microbiota and social network $[4,14,18]$

A recently emerged model for gut microbiome studies, the honey bee worker hindgut microbiota is highly predictable by both taxonomy and structure, comprised almost exclusively of five core phylotypes represented in every study [7,12,20-24]. Occurring downstream of excreted host waste, the ileum and rectum each support a distinct microbiota composed of three core phylotypes, and referred to as the "core hindgut microbiota" throughout this manuscript; In the rectum, Lactobacillus firm5, Lactobacillus Firm4, Bifidobacterium asteroides dominate, while Snodgrassella alvi, Gilliamella apicola and Lactobacillus Firm5 dominate the ileum. These five hindgut phylotypes are essential to the health of the individual worker and colony, and occur throughout the colony and hive environment, facilitating generational transmission [25-27]. Similar to the hindgut, a variety of niches throughout the colony and hive also contain a unique and predictable set of phylotypes $[4,19,22,28-30]$. The honey bee maintains a strict relationship with the microbes in its hindgut, and we predict similar functional pressure exists to control the microbiota of the colony environment.

Honey bees are a "colony in a hive"[31]. The colony is the animated genome of Apis mellifera, the hive is a built structure that contains developing young larvae, pupae and stored food. Due to physical continuity, the colony (and gut) microbiota persists in and on the bodies of adult worker bees; in the secretory glands, on the mouthparts, on the exoskeleton, and in the guts and hemolymph. Colonies reproduce by budding when thousands of adult worker bees depart the overgrown parent hive and build a new hive to perpetuate the lineage. Larvae are left behind in this process, perhaps one reason that larval microbiomes are unpredictable relative to that of workers [19,32]. From a perspective of microbial evolution, worker bees are the continuous microbial niche. With the establishment of a new hive, the colony microbiome carried by the workers populates the hive environment. Referred to as the colony 
microbiota throughout this manuscript, we argue that a variety of low abundance niches throughout the colony and hive possess a host-adapted microbiome with a large impact on colony health. The colony microbiome populates beebread, honey, jelly, queens and larvae $[13,14,18,19,22,28,32,33]$. It is comprised of hundreds of microbial species that only attain high numbers at a particular space and time, or in the context of opportunism and disease [34-40]. Here we hypothesize that the microbiotas that populate the colony and hive are co-adapted to the honey bee environment including host-generated enzymes and peptides that function in social immunity [41].

A combination of selective culturing and next generation sequencing provides insight into the breadth and diversity of the colony microbiota. A typical 16S rRNA gene amplicon library of the whole worker gut reveals a taxonomic handful (5-9) of phylotypes (OTUs) that account for $95-97 \%$ of the whole gut microbiota [7]. The remaining 3-5\% tail of the distribution, also referred to as the rare biosphere, can contain thousands of bacterial species, many of which are easily cultured $[18,19,22,38,40,42,43]$. This "rare biosphere" [44] is comprised of both microbes from the pollination environment and a more predictable set of phylotypes adapted to the colony and hive environment. A recently discovered exemplar, Serratia marscescens (Enterobacteriaceae), was shown to possess a suite of honey bee colonyassociated survival genes not found in any other strain of $S$. marcescens [45]. Although rarely apparent with next generation sequencing of the whole gut, this bacterial strain is a very successful and widespread opportunist of honey bees, becoming highly pathogenic when the integrity of the gut microbiota or host health is compromised [12]. Consistent with this finding, the hive is host to a variety of Enterobacteriaceae and other groups of well-known opportunistic or pathogenic Gammaproteobacteria $[43,46,47]$. Many of these OTUs occur frequently across studies suggesting they are part of the taxonomically consistent colony microbiota.

Core to the colony microbiota, Lactobacillus kunkeei and Parasaccharibacter apium (synonym for Bombella apis) reflect a deep ecological and evolutionary history with bee species and the pollination environment [18,32,48-51]. These two species are part of a healthy larval and queen microbiota [33]. Their growth is either enhanced or unaffected by honey and jelly, while taxonomically similar non-colony microbes are inhibited [32]. P. apium dominates the mouthparts of workers and queens, and can inhibit specialized fungal pathogens $[15,33,52]$ suggesting a co-evolved protective role. Our research suggests that these two bacteria, among many others, are in somewhat continuous contact with hygienic structures of workers, larvae and queens like the mouthparts, midguts, social stomach, HPG, and leg combs. Well adapted to high solute concentrations and bioactive properties of the hive, the colony microbiota may survive or even proliferate in antimicrobial hive materials like plant resins (propolis), jelly, and honey $[4,32,53,54]$.

Honey bee life-history and aging is extremely plastic; queens can live for years, and workers also exhibit considerable longevity differences associated with age, task, overwintering and forage dearth [55-58]. Similar to other model systems, the hindgut microbiota tracks the physiology of honey bee behavioral and reproductive phenotypes associated with age and nutritional state [30,33]. Worker bees acquire their highly structured hindgut microbiota in the first 1-4 days of adult life concurrent with the consumption of 
beebread; pollen, honey and worker secretions $[25,26]$. Host digested beebread is converted to an internal storage molecule, vitellogenin $(\mathrm{Vg})$, a large lipo-glyco-phosphoprotein. The role of $\mathrm{Vg}$ varies by tissue and caste and is associated with antioxidant, antimicrobial, and anti-inflammatory properties [59]. Workers raised in sterile conditions and fed sterile beebread do not establish a typical gut microbiota, and show deficient central metabolism including decreased insulin signaling and $\mathrm{Vg}$ production [27], and as a social consequence, deficient HPG secretions.

The HPG can express a broad variety of nutritional and antimicrobial combinations in response to colony needs. Jelly contains antimicrobial peptides and social hygienic enzymes glucose oxidase (GOX), and superoxide dismutase (SOD). Mixed with glucose in honey, GOX produces gluconic acid and hydrogen peroxide. The honey bee social environment is coated with $\mathrm{GOX}$ and $\mathrm{H}_{2} \mathrm{O}_{2}$ providing a generalized social immune barrier [1,60-62]. Phenotypic plasticity within the worker caste is reflected in HPG gene expression; young nurses produce copious amounts of nutrient rich jelly, but the HPG shrinks in older foragers and secretes enzymes associated with honey processing $[63,64]$. The HPG of workers can resume past physiological states associated with youth, or shift forward to assume the task of an older bee [65]. The gland can also react more proximally to colony-level challenge associated with a variety of social processes like emergency queen rearing $[66,67]$. In addition to providing shared nutrition, jelly may transmit immune training molecular patterns across generations, extend life expectancy, modulate microbiota structure and prevent opportunistic disease[67-69]. Gene expression associated with individual and social immunity is costly, and only generated by well-nourished individuals $[61,70]$. Because internal vitellogenin stores overwinter rely on nutrition in the fall, the availability of pollen on the landscape is the major factor in brood production, colony growth and disease resistance [71].

Honey bee colonies respond rapidly to environmental conditions. The proximal cue of artificial rainfall causes a shift to conservation physiology in a matter of hours [72]. Similarly, persistent low temperatures shift physiology towards colony thermoregulation and resource conservation including the production of the long-lived diutinus worker phenotype. Diutinus workers consume and digest pollen in the fall, or at the beginning of a pollen dearth, then store the nutrition internally throughout the winter months to provide for the growing colony when environmental conditions improve. With the coming of winter, pollen diversity and nutrition disappear completely across the northern landscape, and decrease drastically on the southern landscape. While colony function in cold winter environments is well defined, mild overwintering conditions found in the southern US involve a variety of indistinct or conflicting environmental cues, including warm daily temps, and the availability of pollen and nectar on the landscape. Subsequently, brood rearing over winter commonly discontinues in northern climates, but continues at significantly reduced levels in southern climates, stimulating foraging behavior throughout the winter [73,74]. The presence of brood in the hive environment accelerates both behavioral and cellular senescence among worker bees [55]. After approximately 10 days of foraging, workers experience a sharp increase in mortality [55]. The forager gut microbiota differs from that of a nurse, likely due to taskassociated metabolism and senescence [30,33]. Incomplete nutrition and fluctuations in temperature or water availability associated with foraging and brood rearing overwinter may also affect the colony and 
gut microbiota producing an environment conducive to the growth of opportunists. Colonies weakened by less than adequate nutrition and cold temperatures are more susceptible to disease and dysentery, and if they survive the winter, may build back slowly in the spring.

In northern climates, the cohort of workers emerging in early winter express the diutinus phenotype, and can live $8 X$ longer (240 days) than a worker during spring/summer colony growth $[75,76]$. Although a critical point in the life cycle, variation in gut and colony microbiota and physiology that accompanies this process is relatively unknown, as is the HPG gene expression of diutinus workers overwinter [77,78]. A recent investigation of the diutinus hindgut microbiota implied healthy overwintering physiology in cold $\left(7^{\circ} \mathrm{C}\right)$ indoor climates, but the proliferation of opportunistic bacteria associated with southern outdoor overwintering [8]. However, the opportunistic microbes were at extremely low abundance in the hindgut relative to the core microbiota. In this contribution, we investigate these same samples more deeply by examining the change in worker mouth and midgut microbiotas, and detailing the associated change in gene expression from the hypopharygeal gland, a secretory gland that interfaces with the extended social environment on many levels. Like other examples from social insects $[5,6]$, we hypothesize that HPG social secretions nurture symbionts native to the alimentary tract, but are negatively associated with opportunists in the colony environment.

\section{Methods}

To gain an understanding of host-microbial interaction overwinter, we performed two separate but related experiments (Fig. 1). We designed the first experiment to provide perspective on the relationships of mouth and midgut microbiota with social gene expression. We quantified HPG gene expression and the microbiotas associated with the long-lived diutinus phenotype in warm winter conditions; The second experiment compared HPG expression and various microbiota characteristics of the midgut associated with full-sized colonies placed in cold indoor climate-controlled wintering, and warm outdoor wintering. These results are associated with a published companion paper that sequenced the ileums and rectums from the same experimental samples [8]. Briefly, those results revealed little change in the hindgut microbiota of worker bees overwinter regardless of climate or age. However, the authors suggested the potential for compromised host physiology in warm southern climates, revealed by poor longevity overwinter and significantly increased fungal load correlated with an increase in putatively opportunistic Enterobacteriaceae. This manuscript more fully explores the microbiomes and host response associated with microbial opportunism and fungal growth.

\section{Experiment 1: Known age cohort}

We used four observation hives to follow a known age (KA) cohort and validate chronological age. Colonies comprised of three or four frames containing brood, plentiful honey and beebread, were kept in greenhouses at the Carl Hayden Bee Research Center, Tucson AZ with exposure to diurnal cycles, access to the foraging environment and a small space heater for rare nights below freezing. To control for age in the observation hive, newly emerged winged adults were sourced from brood frames of 20 healthy 
colonies. Late stage pupae emerged naturally from their natal frame over a period of $\leq 24$ hours while housed in a humidity $(50 \%)$ and temperature-controlled $\left(35^{\circ} \mathrm{C}\right)$ room. All newly emerged bees were collected into a single container and randomized prior to colony assignment. We painted the thoraces of 2,000 newly emerged bees and divided them equally among four observation colonies. Adult worker bees were introduced into observation hives in early December, then sampled from Dec 22nd 2015 - Feb 10th 2016. Samples of marked bees were collected at 19,33, 50 and 70 days of age. Our 19 Day-old sample represents the age when workers have expelled the pollen from their guts and transitioned to foraging, while 33 days is the expected longevity of foragers. In the previous study, we estimated that only $10 \%$ of introduced bees survived until 50 days of age [8]. Thus our 50 and 70 day old samples were comprised of the longest-lived bees relative to average life expectancy in southern climates. From this sample set, we quantified the change in gene expression overwinter of host genes related to reactive oxygen species, and antimicrobial peptide (AMP) expression. The ileum and rectum microbiota from these same worker samples (KA) was remarkably stable from 19-70 days of age while fungal load and bacterial diversity decreased significantly overwinter in the hindgut.

\section{Experiment 2: Overwintering climate comparison}

In a second experiment, we hypothesized that overwintering climate (environment) affects the colony microbiota. More specifically, that the midgut microbiomes associated with warm vs. cold overwintering would differ as a result of temperature and task differences experienced by the hive. We compared the midgut microbiota of colonies from southern outdoor climates to colonies kept indoors overwinter in cold climate controlled conditions. Because honey bees are homeotherms, they regulate hive temperature by clustering together and shivering their flight muscles to generate heat [79]. Climate controlled overwintering of honey bee colonies is a highly successful strategy for commercial beekeepers, and much of the knowledge about wintering honey bees is focused on cold tolerance in northern climates. Colonies overwintered in warm southern climates are exposed to diurnal cycles of light and temperature, and can leave the hive to defecate and forage for resources. They typically maintain a weak foraging effort overwinter, but still consume simple sugars and cluster for warmth mostly at night. All colonies in this experiment had access to honey and beebread overwinter, but the cold winter colonies became broodless, while the warm winter colonies continued to forage and rear small numbers of brood throughout the winter $[73,74]$. All full size colonies in both environments were $6+$ frames of bees at the beginning of the experiment with no signs of disease.

The warm overwintering (WW) environment was the Santa Rita Experimental Range in southern Arizona $31^{\circ} 46^{\prime} 38^{\prime \prime} \mathrm{N}, 110^{\circ} 51^{\prime} 47^{\prime \prime} \mathrm{W}$. We collected worker samples in mid-December 2015 and mid-February 2016. We placed cold winter (CW) colonies in a climate controlled storage facility at a constant $7^{\circ} \mathrm{C}$ and $25 \%$ relative humidity with no access to environmental cues. Worker bees were sampled just prior to entering the cold storage warehouse in Firth, Idaho, USA, $43^{\circ} 18^{\prime} 45^{\prime \prime} \mathrm{N}, 112^{\circ} 09^{\prime} 20^{\prime \prime} \mathrm{W}$ in early winter, mid-October 2015 , and directly after they were removed from cold storage and transported to the almond orchards in late winter, mid-February 2016, near Snelling, California, USA, $37^{\circ} 31^{\prime} 33^{\prime \prime} \mathrm{N}, 120^{\circ} 31^{\prime} 52^{\prime \prime} \mathrm{W}$. Thus, we assume that the $\mathrm{CW}$ worker samples represent the diutinus phenotype in early and late winter. From the edge of 
the brood nest, we sampled worker bees from 16 colonies per time point, per climate for 64 total colony samples. The hindgut microbiotas of early winter bees did not differ by climate/locale but fungi increased significantly overwinter in the hindguts of WW samples, concurrent with a slight but significant increase in an unknown Gilliamella spp. and Enterobacteriaceae [8].

\section{DNA analysis}

Two honey bee worker tissues were used for microbial DNA analysis, the mouthparts and midguts. Immediately after being removed from - $80 \mathrm{C}$ individual bees were surface sterilized and dissected in $95 \%$ ethanol using sterile forceps and dissection scissors. We immediately placed all tissues into a $2 \mathrm{ml}$ bead beating tube containing 100ul of $0.1 \mathrm{~mm}$ silica beads and 300ul of 1X TE buffer $(10 \mathrm{mM}$ Tris- $\mathrm{HCl}, 1 \mathrm{mM}$ EDTA) and immediately frozen on dry ice. All dissected tissues were stored at $-80 \mathrm{C}$. Prior to DNA extraction, each sample was bead beaten for a total of $2 \mathrm{~min}$ in $30 \mathrm{sec}$ intervals. To each sample, $100 \mu \mathrm{l}$ lysis buffer (20 mM Tris-HCl, 2 mM EDTA, $5 \%$ Triton X-100, 80 mg/ml lysozyme, pH 8.0) was added and the samples were incubated at $37^{\circ} \mathrm{C}$ for $30 \mathrm{~min}$. Total genomic DNA was extracted using a Fermentas GeneJet Genomic DNA Purification Kit (\#K0722) following the protocol for gram-positive bacteria. Miseq amplification and analysis was performed as in [8]. We estimated the size of the bacterial/fungal communities in the ileum and rectum using degenerate primers [80, 81]. We amplified the $16 \mathrm{~s}$ gene template using forward primer 27F (5'-AGAGTTTGATCCCTCAG-3') and reverse primer 1522R (5'AAGGAGGTGATCCAGCCGCA - $3^{\prime}$ ). For fungal quantification, we extracted total genomic DNA from $S$. cerevisiae cells. The $18 \mathrm{~s}$ gene template was amplified using forward primer PanFungal_18S_F (5'GGRAAACTCACCAGGTCCAG - 3') and reverse primer PanFungal_18S_R (5'-GSWCTATCCCCAKCACGA-3'). We created plasmid vectors using Invitrogen's $\mathrm{pCR}^{\mathrm{TM}} 2.1 \mathrm{TOPO}^{\mathrm{TM}}$ cloning vectors per the manufacture's specifications.

\section{Microbiota sequencing}

The V6-V8 region of the 16S rRNA gene was amplified using universal (degenerate) PCR primers 799F (acCMGGATTAGATACCCKG) and bac1193R (CRTCCMCACCTTCCTC). We amplified DNA using the HotStarTaq Plus Master Mix Kit (Qiagen, Germantown, MD, USA) under the following conditions: $94 \mathrm{C}$ for $3 \mathrm{~min}$, followed by 28 cycles of $94 \mathrm{C}$ for $30 \mathrm{~s}, 53 \mathrm{C}$ for $40 \mathrm{~s}$ and $72 \mathrm{C}$ for $1 \mathrm{~min}$, with a final elongation step at $72 \mathrm{C}$ for $5 \mathrm{~min}$. We used the PCR products to prepare DNA libraries following Illumina MiSeq DNA library preparation protocol. Sequencing was performed at the University of Arizona Genetics Core (UAGC) on a MiSeq following the manufacturer's guidelines. Resulting sequences were processed using MOTHUR v1.43. [82]. Forward and reverse reads were joined using the make.contigs command. Then the first and last five bases pairs were removed using the SED command in unix. Sequences were screened (screen.seqs) to remove any sequences containing ambiguous bases. Unique sequences were generated using the unique.seqs command. Sequences were aligned to Silva SSUREF database v102 [83] using the align.seqs command. Sequences not overlapping in the same region and columns not containing data were removed using the filter.seqs command. Sequences were pre-clustered using the pre.culster command. Chimeras were removed using UCHIME [84] and any sequences of non-bacterial origin were removed using the remove.seqs command. All remaining sequences were classified using the 
classify.seqs command. All sequences with only one or two (single/doubletons) associated reads were removed using the AWK command in unix. A distance matrix was constructed for the aligned sequences using the dist.seqs command. Sequences were classified with the RDP Naive Bayesian Classifier [85] using a manually constructed training set containing sequences sourced from the greengenes $16 \mathrm{~S}$ rRNA database [86], the RDP version 9 training set, and all full length honeybee-associated gut microbiota listed in NCBI. Operational taxonomic units (OTUs) were generated using the cluster command. Representative sequences for each OTU were generated using the get.oturep command.

\section{Expression analysis}

RNA was extracted from the hypopharyngeal glands of all individuals, and the midguts were used for microbiota sequencing. We also sequenced the microbiotas of mouthpart tissues from KA samples. Heads were surface sterilized and dissected in RNAlater ${ }^{\text {TM }}$ using sterile forceps and dissection scissors. All samples were immediately placed into a $1.5 \mathrm{ml}$ centrifuge tube containing $200 \mu \mathrm{L}$ of Fermentas Lysis Buffer supplemented with $\beta$-mercaptoethanol and immediately frozen on dry ice. All samples were stored at $-80^{\circ} \mathrm{C}$. Total RNA was extracted using a Fermentas GeneJet RNA Purification Kit (\#K0732) following the protocol for Total Insect RNA Purification. Complementary DNA (cDNA) was generated using the Thermo Scientific RevertAid First Strand cDNA Synthesis Kit (\#K1622) following the First Strand cDNA Synthesis protocol. We quantified the expression of eight genes relative to the typically used housekeeping gene $\beta$-actin: three antimicrobial peptides; Hymenoptaecin, Defensin-1 and Abaecin; three antioxidants; Catalase, Zn/Cu Superoxide Dismutase (Zn/CuSOD) and Mn Superoxide Dismutase (MnSOD); the redox "social immunity" enzyme Glucose Oxidase (GOX) and finally Vitellogenin ( $\mathrm{Vg}$ ) as a marker of nutritional state. Briefly, all reactions were performed in a 12ul volume (6ul of Bio Rad iTaq Universal SYBR Green Supermix, 0.5ul of 10uM forward and reverse primer [see [87] for primer details], $3 \mathrm{ul}$ of molecular grade water and $2 \mathrm{ul}$ of template). Cycle conditions were run as described in [87]; $95^{\circ} \mathrm{C}$ for $30 \mathrm{~s}$ and then $40 \mathrm{x}$ of $95^{\circ} \mathrm{C}$ for $20 \mathrm{~s}$ and $60^{\circ} \mathrm{C}$ for $30 \mathrm{~s}$. Amplification was normalized to $\beta$-actin expression.

\section{Nosema quantification}

The midgut is the site of Nosema infection, a highly specialized fungal microsporidian that is a ubiquitous opportunist of honey bee midguts. To determine Nosema infection status in the midgut we ran a modified version of the qPCR protocol reported in [88]. For each $10 \mu \mathrm{l}$ reaction we used $5 \mu \mathrm{l}$ of Luna qPCR master mix (New England Biolabs), $0.25 \mu \mathrm{M}$ of each primer, $1 \mu \mathrm{l}$ of template and $3.5 \mu \mathrm{l}$ molecular grade water. We used $N$. ceranae specific primers NcF (AAGAGTGAGACCTATCAGCTAGTTG) and NcR (CCGTCTCTCAGGCTCCTTCTC) and $N$. apis specific primers NaF (GCCCTCCATAATAAGAGTGTCCAC) and $\mathrm{NaR}$ (ATCTCTCATCCCAAGA). To confirm efficiencies reported in [88] we ran a temperature and concentration gradient qPCR with a known Nosema rich DNA sample. Amplification efficiency was calculated by the CFX manager software and were close to $100 \%$ ( $97.1 \%$ and $98.3 \%$ respectively). Using a CFX96 real time system (BioRad, Hercules, CA) we ran the following thermocycler program: $95^{\circ} \mathrm{C}$ for 3 minutes followed by 40 cycles of $95^{\circ} \mathrm{C}$ for 10 seconds and $63^{\circ} \mathrm{C}$ for 30 seconds. Each sample and negative controls were run in triplicate. Using the same reagent mixture (with a $57^{\circ} \mathrm{C}$ annealing/extension step), we used actin specific primers ActinF (TGCCAACACTGTCCTTTCTG) and ActinR 
(AGAATTGACCCACCAATCCA). We used the average of the three reactions to determine $N$. ceranae load relative to $\beta$-actin expression. We compared the relative qPCR measures to a previous microscopic assessment of Nosema abundance based spore counts from midgut samples of (CW) workers overwintered indoors at $7^{\circ} \mathrm{C}$ and $25 \% \mathrm{RH}$.

\section{Statistical Analysis}

We analyzed microbial community structure and abundance with two different approaches: MANOVA performed on centered log ratios and non-parametric Wilcoxon tests. The MANOVA accounts for microbiota structure while the Wilcoxon test examines absolute abundance without regard to microbiota structure. We compared differences in the microbial community structure by known chronological age (KA samples) as well as within, and between WW and CW environments. To allow the use of parametric multivariate analyses [89], we converted bacterial abundances to ratio abundances among all OTUs [90] using the software CoDaPack's centered log-ratio (CLR) transformation [91]. We compared microbiota structure by chronological age (known age cohort) and season (pre/post winter) within and between climates using one-way MANOVA. Pillai's Trace test statistic was used for all MANOVA's to account for deviations in normality and homogeneity of covariance. Subsequent univariate tests followed by FDR correction for multiple comparisons were used to explore differences between dependent variables.

We compared total microbial load for bacteria, fungi and Nosema using one-way ANOVA (FDR corrected for multiple comparisons). All analyses were conducted in either JMP_v13 (JMP_ 1989-2007) and/or SAS_ v9.4 (2013). Pillai's Trace test statistic was used for all MANOVAs to account for deviations in normality and homogeneity of covariance. Statistically significant MANOVA results were further analyzed with pairwise ANOVA tests followed by FDR correction for multiple comparisons. We analyzed total cell number using pairwise Wilcoxon tests (Steel- Dwass correction for multiple comparisons). To normalize to absolute abundance, the proportional abundance of OTUs returned by amplicon sequencing was multiplied by the total bacterial 16S rRNA gene copies determined with qPCR for each individual tissue type. To account for variability in 16S copy numbers across taxa the $16 \mathrm{~S}$ total was divided by the number of 16S rRNA gene copy numbers present within each bacterial genome. All core phylotypes contain four 16S rRNA gene copies except $B$. asteroides (2). Copy number of the remaining taxa were determined using the average copy number according to taxonomic level on NCBI: L. kunkeei $=5$, Parasaccharibacter apium, a synonym of Bombella apis $=1$, Actinobacteria $=2.9$, Enterobacteriales $=2$ and Xanthomonadaceae $=2.2$. The remaining OTUs (14-6294) were summed, and assigned a gene copy number of 4.2, the average for all bacteria [92]. This value represents a general measure of diversity abundance as it contains $>99 \%$ of the OTUs. To examine hypotheses of host microbial interaction, we generated Spearman's rank correlation coefficient among the dependent variables independently for each treatment condition, and for the entire data set.

\section{Results}

\section{Experiment 1: Known age cohort}


We deep-sequenced the mouthpart and midgut microbiota of aging worker bees overwintered in southern Arizona. We sampled known age (KA) diutinus workers as the winter progressed at 19, 33, 50 and 70 days of age (Fig. 1, Experiment 1). Bacterial diversity on the mouthparts was greatest in 33-day-old bees and decreased in older bees (Fig. 2). Based on the total number of unique 16S rRNA gene sequences found in each niche, bacterial diversity was positively associated between the mouthparts and midguts of known age bees $\left(R s q=0.25, F_{2,36}=12.0, p=0.001\right)$. The mean number of unique OTUs detected on the mouth not differ from that detected in the midgut and did not change with age $(n=38$, mouth $=57$, midgut $=62)$. Both the mouth and midgut environments were comprised of a taxonomic variety of bacteria, including all five of the core hindgut phylotypes (Fig. 3). The five core hindgut bacteria were strongly inter-correlated on both the mouth and the midgut, as were $P$. apium and L. kunkeei (Table S1). Based on a Wilcoxon rank sum test comparing 19/33 day old bees to 50/70 day old bees, bacterial load remained steady on the mouth with age but increased in the midgut $\left(\mathrm{W}_{46}=166, \mathrm{p}=0.03\right)$. In contrast, total fungal load decreased slowly and significantly on the mouthparts of aging bees $\left(W_{46}=114, p=0.0004\right)$ but remained steady in the midgut (Fig. 4). In both the mouth and midgut of aging bees, fungal load was positively associated with bacterial diversity abundance (Table S1).

The mouthpart microbiota was comprised of $P$. apium, Actinomycetales, Xanthomonadaceae, Delftia (Comamonadaceae), an unknown Gilliamella spp., and L. kunkeei. Enterobacteriaceae was at low abundance on $95 \%$ of the mouthparts, and Actinomycetales, Xanthomonadaceae and Delftia had $100 \%$ prevalence and relatively even abundance. P. apium and L. kunkeei were both prevalent on the mouth but varied considerably in absolute abundance (Fig. 3, Table S2). The mouth microbiota of the aging bee (KA) differed from early to late winter. MANOVA results reflect the change in particular OTUs relative to other members of the microbiota, while Wilcoxon tests do not account for the group effect (Table S2). On the mouthparts of aging bees, Actinomycetales and the unknown Gilliamella spp. increased while Xanthomonadaceae decreased from twenty-six to nine percent of the total mouthpart community. Relative abundance of Enterobacteriaceae on the mouth also decreased with age (Fig. 3, Table S2). We examined the aging bees by predicted task, assuming 19-33 days old bees were potential foragers or young diutinus workers and 50-70 day old bees were long-lived diutinus workers. According to this grouping, diversity abundance on the mouth decreased with age, while the relative abundance of $L$. firm5, $L$. firm4 and B. asteroides on the mouth also decreased with age (Table S2).

The midgut of aging diutinus workers supported Enterobacteriaceae, P. apium, an unknown Gilliamella spp. and L. kunkeei. The triad signature of Actinomycetales, Xanthomonadaceae, and Delftia was present in nearly every midgut at low relative abundance (Table S2). All five of the core hindgut bacteria increased with age (Fig. 3). Snodgrassella alvi and G. apicola increased significantly, while L. firm5 and $B$. asteroides also increased, trending towards significance (Table S2). A putative midgut opportunist; Enterobacteriaceae also increased markedly with age. Although at low absolute abundance in KA midguts, the relative abundance of both Delftia (Comamonadaceae) and Xanthomonadaceae decreased with age overwinter. Both Lachnospiraceae and Serratia were at low abundance in the KA mouthparts and midguts, present in $<50 \%$ of samples (Table S2). 
Nosema ceranae, a ubiquitous midgut pathogen, was at generally low absolute abundance in the midgut of aging bees. Many samples from all KA age groups did not rise above the limit of detection (Table S3). Nonetheless, $N$. ceranae levels differed significantly among age classes, peaking at 33 days of age and declining thereafter. Nineteen and 70-day-old bees contained significantly less $N$. ceranae than 33-day-old bees representing diutinus "mid-life" or forager-aged workers (Table S3).

\section{Experiment 1: Known age cohort gene expression}

To examine the hypothesis that gene expression of long-lived honey bees affects the colony and/or gut microbiome, we examined associations of HPG gene expression with the aging diutinus microbiota (KA samples) of the mouth and midgut overwinter. We determined the relative expression of HPG genes with a hypothesized role in structuring the colony microbiome. The relative expression of five genes involved in ROS generation and AMP production increased significantly with age (Table 1, Table S4). ROS associated gene expression had a strong and significant negative association with both bacterial diversity abundance and fungal load on the mouth (Table 2, Table S1). Actinomycetales increased significantly with age on the mouth and was positively associated with ROS gene expression. Xanthomonadaceae Decreased significantly with age on the mouthparts, and was negatively correlated with ROS associated gene expression (Table 2). Enterobacteriacae abundance was also negatively associated with ROS gene expression on the mouth trending toward significance (Table 2, Table S1). 
Table 1

Change $(\Delta)$ in hypopharygeal gland gene expression overwinter.

\begin{tabular}{|c|c|c|c|c|c|c|c|c|c|}
\hline \multirow{2}{*}{$\begin{array}{l}\text { Change }(\Delta) \text { overwinter } \\
\text { Gene }\end{array}$} & \multicolumn{3}{|c|}{$\begin{array}{l}\text { Warm Winter } \\
\text { Known age* }\end{array}$} & \multicolumn{3}{|c|}{$\begin{array}{l}\text { Warm winter } \\
\text { Random sample }\end{array}$} & \multicolumn{3}{|c|}{$\begin{array}{l}\text { Cold winter } \\
\text { Random sample }\end{array}$} \\
\hline & Z & $\mathrm{p}$ & $\Delta$ & Z & $\mathrm{p}$ & $\Delta$ & Z & $p$ & $\Delta$ \\
\hline \multicolumn{10}{|l|}{ Nutritional State } \\
\hline Vitellogenin & 0.69 & 0.49 & NC & -2.00 & 0.05 & $\downarrow$ & 0.42 & 0.68 & NC \\
\hline \multicolumn{10}{|l|}{ Antimicrobial Peptides } \\
\hline Hymenoptaecin & 2.69 & 0.007 & $\uparrow$ & -1.52 & 0.13 & $\downarrow$ & 1.34 & 0.18 & $\downarrow$ \\
\hline Defensin-1 & -0.67 & 0.53 & NC & 1.62 & 0.11 & $\downarrow$ & 2.18 & 0.03 & $\downarrow$ \\
\hline Abaecin & 2.87 & 0.004 & $\uparrow$ & -2.21 & 0.03 & $\uparrow$ & 1.42 & 0.16 & $\downarrow$ \\
\hline \multicolumn{10}{|l|}{ Oxidative State } \\
\hline Glucose Oxidase & 2.80 & 0.005 & $\uparrow$ & 0.02 & 0.98 & NC & 2.05 & 0.04 & $\downarrow$ \\
\hline $\mathrm{Cu} / \mathrm{ZnSOD}$ & 5.14 & 0.0001 & $\uparrow$ & -0.58 & 0.56 & NC & -0.18 & 0.86 & NC \\
\hline MnSOD & 5.57 & 0.0001 & $\uparrow$ & 1.10 & 0.27 & NC & -0.66 & 0.51 & NC \\
\hline
\end{tabular}


Table 2

Correlations ${ }^{\dagger}$ of diutinus HPG immune gene expression with microbial abundance and metrics.

\begin{tabular}{|c|c|c|c|c|c|c|}
\hline \multirow[t]{2}{*}{ Gene } & \multicolumn{3}{|l|}{ Known Age Mouthparts } & \multicolumn{3}{|l|}{ Known Age Midguts } \\
\hline & Dependent variable & Rs & p & Dependent variable & Rs & p \\
\hline \multicolumn{7}{|c|}{ Nutritional State } \\
\hline Vitellogenin & \multicolumn{3}{|l|}{ No strong associations } & \multicolumn{3}{|l|}{ No strong associations } \\
\hline \multicolumn{7}{|c|}{ Antimicrobial Peptides } \\
\hline \multirow[t]{3}{*}{ Abaecin } & Actinomycetales & 0.29 & 0.05 & Nosema ceranae & -0.36 & 0.01 \\
\hline & P. apium & -0.24 & 0.11 & P. apium & -0.33 & 0.04 \\
\hline & & & & Bacterial abundance & 0.30 & 0.05 \\
\hline Hymenoptacin & Actinomycetales & 0.38 & 0.01 & Nosema ceranae & -0.38 & 0.01 \\
\hline Defensin-1 & $\begin{array}{l}\text { Lactobacillus } \\
\text { kunkeei }\end{array}$ & -0.31 & 0.04 & Lactobacillus kunkeei & -0.30 & 0.07 \\
\hline \multicolumn{7}{|l|}{ Oxidative State } \\
\hline \multirow[t]{6}{*}{ GOX } & Fungal abundance & -0.23 & 0.13 & Snodgrassella alvi* & 0.54 & 0.0004 \\
\hline & Diversity abundance & -0.32 & 0.03 & B. asteroides* & 0.45 & 0.004 \\
\hline & Xanthomonadaceae & -0.37 & 0.01 & Gilliamella apicola* & 0.44 & 0.006 \\
\hline & P. apium & -0.14 & 0.33 & Lactobacillus firm4* & 0.33 & 0.04 \\
\hline & L. kunkeei & -0.11 & 0.44 & Lactobacillus firm5* & 0.30 & 0.07 \\
\hline & & & & Nosema ceranae & -0.40 & 0.007 \\
\hline \multirow{5}{*}{$\begin{array}{l}\mathrm{Cu} / \mathrm{Zn} \\
\text { SOD }\end{array}$} & Fungal abundance & -0.48 & 0.0008 & $\begin{array}{l}\text { Core hindgut } \\
\text { bacteria* }\end{array}$ & 0.36 & 0.05 \\
\hline & Diversity abundance & -0.38 & 0.01 & Snodgrassella alvi & 0.53 & 0.0006 \\
\hline & Xanthomonadaceae & -0.50 & 0.0004 & Bacterial abundance & 0.33 & 0.02 \\
\hline & Enterobacteriaceae & -0.26 & 0.08 & Enterobacteriaceae & 0.32 & 0.05 \\
\hline & Actinomycetales & 0.43 & 0.003 & Nosema ceranae & -0.32 & 0.03 \\
\hline
\end{tabular}

† Spearmans correlations based on diutinus worker (KA) samples. See Table S1 for a complete list of values.

* Values for the core hindgut bacteria are averages based on five OTUs (phylotypes); S. alvi is one of the five.

Strongest detected relationship of mouth microbiota with Catalase expression 


\begin{tabular}{|c|c|c|c|c|c|c|}
\hline \multirow{2}{*}{$\begin{array}{l}\text { Gene } \\
\text { Mn SOD }\end{array}$} & \multicolumn{3}{|c|}{ Known Age Mouthparts } & \multicolumn{3}{|l|}{ Known Age Midguts } \\
\hline & Fungal abundance & -0.48 & 0.0008 & $\begin{array}{l}\text { Core hindgut } \\
\text { bacteria* }\end{array}$ & 0.38 & 0.05 \\
\hline & Diversity abundance & -0.41 & 0.004 & Snodgrassella alvi & 0.54 & 0.0004 \\
\hline & Xanthomonadaceae & -0.55 & 0.0001 & Bacterial abundance & 0.31 & 0.04 \\
\hline & Enterobacteriaceae & -0.26 & 0.08 & Enterobacteriaceae & 0.36 & 0.03 \\
\hline & Actinomycetales & 0.52 & 0.0002 & Nosema ceranae & -0.30 & 0.04 \\
\hline \multirow[t]{3}{*}{ CAT } & $\begin{array}{l}\text { Diversity } \\
\text { abundance^ }\end{array}$ & 0.23 & 0.11 & Lactobacillus kunkeei & 0.43 & 0.007 \\
\hline & & & & Bacterial Diversity & 0.34 & 0.04 \\
\hline & & & & Lactobacillus Firm5 & -0.38 & 0.02 \\
\hline \multicolumn{7}{|c|}{$\begin{array}{l}\text { † Spearmans correlations based on diutinus worker (KA) samples. See Table S1 for a complete list of } \\
\text { values. }\end{array}$} \\
\hline \multicolumn{7}{|c|}{$\begin{array}{l}* \text { Values for the core hindgut bacteria are averages based on five OTUs (phylotypes); } S \text {. alvi is one of } \\
\text { the five. }\end{array}$} \\
\hline
\end{tabular}

The midgut showed very different host-microbial relationships than the mouthparts. Both GOX and SOD expression (CuZnSOD and MnSOD) were strongly and positively associated with abundance of the core five hindgut phylotypes in the midgut (Table 2, Table S1). The strongest positive relationship within this core group was Snodgrassella alvi, an obligate aerobe (Table 2). In contrast to the mouth, Enterobacteriaceae and ROS gene expression were positively correlated in the midgut. Because both the core hindgut bacteria and Enterobacteriaceae increased in the midguts of aging bees overwinter, total bacterial load in the midgut was also positively associated with ROS gene expression. The expression of both SOD genes was strongly intercorrelated in both the mouth and midgut. Both were also strongly and positively correlated with the group of five core hindgut bacteria, as was glucose oxidase, widely considered the standard enzyme for social hygiene (Table 2, Table S1).

Relative to actin, the expression of two of three measured AMPs increased significantly with age, Hymenoptaecin and Abaecin (Table 1). None of the tested AMPs were significantly correlated with total bacterial or fungal load on the mouth or midgut with the single exception of abaecin, positively correlated with midgut bacterial load (Table 2, Table S1). Most notably, not one of the five core hindgut bacteria was significantly associated with AMP expression on the mouth or in the midgut consistent with their longterm co-evolution with honey bee defensive peptides. However, defensin-1 was negatively correlated with L. kunkeei abundance on the mouth and in the midguts, and to a lesser degree, P. apium. Abaecin expression was negatively correlated with $P$. apium abundance in the midgut. Both Hymenoptaecin and Abaecin were positively associated with the abundance of Actinomycetales on the mouthparts (Table 2). 


\section{Experiment 2: Overwintering climate comparison}

We sequenced the midgut microbiota of worker bees overwintered outdoors in southern Arizona or indoors at $7{ }^{\circ} \mathrm{C}$ and $25 \% \mathrm{RH}$. These samples are referred to throughout the manuscript as the WW and $\mathrm{CW}$ samples (Fig. 1, Experiment 2), and are the same individuals sequenced for ileum and rectum microbiota in a companion manuscript[8]. Based on the total number of unique 16S rRNA gene sequences, or amplicon sequence variants (ASVs) found in each midgut, bacterial diversity increased significantly overwinter in the WW environment (Fig. 2, $\mathrm{t}_{30}=2.89, \mathrm{p}=0.008, \mu=59$ early, 154 late), and decreased significantly in the $\mathrm{CW}$ environment; (Fig. $2, \mathrm{t}_{32}=2.89, \mathrm{p}=0.007, \mu=253$ early, 94 late). Both bacterial and fungal load overwinter remained unchanged in $\mathrm{CW}$ midguts, but increased significantly in WW midguts (Fig. 6, Bacteria: $W_{30}=43, p=0.003$, Fungi: $W_{30}=42, p=0.0008$ ). Fungal load was positively associated with diversity abundance, and both factors increased over winter in WW bees and decreased in CW bees.

Both WW and CW midgut environments were comprised of the same OTUs, including all five core hindgut phylotypes, $P$. apium $=($ Bombella apis), Actinomycetales, Xanthomonadaceae, Delftia (Comamonadaceae), and L. kunkeei. Actinomycetales, Xanthomonadaceae and Delftia had 100\% prevalence and relatively even abundance across both groups (Fig. 5, Table S2). Core hindgut bacteria in the midgut increased in CW bees overwinter, but decreased in WW bees (Table S2).

The midgut microbiota from early to late winter differed between WW and CW climates. MANOVA results reflect the change in particular OTUs relative to other members of the microbiota, while Wilcoxon tests compare absolute abundance and do not account for the group effect (Table S2). According to Wilcoxon analysis, the CW midguts did not differ statistically from early to late winter when comparing OTU absolute abundance and correcting for multiple comparisons (Table S2). Near significance, L. Firm4 increased and $L$. kunkeei decreased overwinter in WW samples. Considering OTU ratio abundance in CW samples, L. firm 5 and $L$. firm 4 increased significantly overwinter, and the other core bacteria trended in the same direction (Fig. 5). L. kunkeei decreased significantly in relative (ratio) abundance as did our measure of diversity abundance, indicating both a loss of diversity and a loss of diversity abundance relative to the midgut microbiota as a whole (Figs. 2 and 5). While the $\mathrm{CW}$ microbiota changed very little in terms of abundance and composition, the colonies overwintered in a warm outdoor environment changed drastically for both measures (Fig. 5).

Rare or absent in the CW samples Enterobacteriaceae and an unknown Gilliamella spp. were abundant in the midguts of late WW samples (Fig. 5). Increasing in absolute abundance from early to late winter (WW) were Enterobacteriaceae, an unnamed Gilliamella spp (3\% different from either G. apis or G. apicola), Gilliamella apicola, P. apium, Actinomycetales and diversity abundance (Table S2). Enterobacteriaceae and the Gilliamella spp. accounted for the vast majority of the bacterial increase in midgut microbiota size overwinter (Fig. 6, Table S2). Although at low abundance in WW midguts, Xanthomonadaceae decreased significantly overwinter. MANOVA comparisons indicate L. Firm5 and L. Firm4 decreased relative to the total microbiota. However, the WW microbiota increased 10X in size overwinter (Fig. 6), such that the absolute cell numbers of L. Firm5 did not differ between treatments, but 
the ratio abundance of L. firm5 relative to the whole community decreased significantly (Fig. 5). L. Firm5 and L. Firm4 decreased significantly in WW midguts overwinter when considered as a proportion of the community whole, as did the less abundant OTUs Xanthomonadaceae and Delftia (Comamonadaceae). Enterobacteriaceae, Gilliamella spp. and Actinomycetales increased in both absolute abundance, and relative to the total community (Table S2).

Associated with small mouthpart microbiomes, Actinomycetales was present in every midgut of the CW samples. Moreover, the CW samples had a signature of three inter-correlated OTUs associated with small, presumably healthy midgut microbiotas; Xanthomonadaceae, Actinomycetales, and Delftia, a Commomonadaceae. These bacteria appear in virtually every next generation sequencing dataset, and are typically more abundant in the HPG, royal jelly, and now seemingly the midguts of bees overwintered indoors at $7^{\circ} \mathrm{C}$.

Levels of Nosema ceranae differed by overwintering climate (Table S3). Similar to many other microbial metrics, levels of $N$. ceranae remained unchanged from early to late winter in the CW samples. In the WW samples, $N$. ceranae increased significantly from early to late winter. Biologically, Nosema ceranae was at low abundance overwinter in both environments based on high Ct values and non-amplification of many samples (Table S3).

\section{Experiment 2: Overwintering climate gene expression}

In the CW indoor environment, HPG expression differed from early to late winter for two of seven genes (Table 1, Table S4). Glucose oxidase, and defensin-1 expression decreased significantly from early to late winter. The remaining genes either decreased slightly in expression or remained unchanged. Gene expression was associated with host microbial metrics. HPG expression of Defensin-1 decreased concurrently overwinter with bacterial diversity in CW midguts (Table 3). GOX expression decreased as $S$. alvi midgut abundance increased. For consideration independent of corrected $\mathrm{p}$-value in the $\mathrm{CW}$ samples, S. alvi was positively associated with total bacterial cell abundance, and GOX expression was negatively associated with the abundance of fungi, Bifidobacterium asteroides, and G. apicola in the midgut. Catalase expression was negatively associated with bacterial diversity in the midgut (Table 3, Table S1). 
Table 3

Correlations $^{\dagger}$ of HPG immune gene expression with microbial abundance and metrics.

\section{Category WW Midgut}

Gene

Dependent variable

Rs

$-0.59$

0.005

$-0.61$

0.003

$-0.56$

0.006

$-0.54$

0.01

Actinomycetales

$-0.47$

Xanthomonadaceae

Enterobacteriaceae

0.45

$-0.52$

$-0.48$

Fungal Abundance

Nosema ceranae

Actinomycetales

Bacterial Diversity

Nosema ceranae

Defensin

Oxidative State

GOX

GOX

Nosema ceranae

Bacterial Diversity

G. apicola

B. asteroides

Fungal Abundance

S. alvi

P. apium

Nosema ceranae

CuZnSOD

\section{CW Midgut}

Dependent variable

Rs

p

\begin{tabular}{|c|c|c|c|c|c|c|}
\hline Abaecin & Xanthomonadaceae & -0.47 & 0.01 & Xanthomonadaceae & -0.05 & 0.79 \\
\hline & Enterobacteriaceae & 0.45 & 0.01 & Enterobacteriaceae* & $\mathrm{N} / \mathrm{A}$ & N/A \\
\hline \multirow[t]{4}{*}{ Hymen } & Bacterial Diversity & -0.52 & 0.004 & Bacterial Diversity & 0.26 & 0.16 \\
\hline & Fungal Abundance & -0.48 & 0.007 & Fungal Abundance & -0.08 & 0.67 \\
\hline & Nosema ceranae & -0.48 & 0.007 & Nosema ceranae & 0.25 & 0.18 \\
\hline & Actinomycetales & -0.39 & 0.04 & Actinomycetales & -0.06 & 0.76 \\
\hline \multirow[t]{2}{*}{ Defensin } & Bacterial Diversity & -0.23 & 0.22 & Bacterial Diversity & 0.51 & 0.005 \\
\hline & Nosema ceranae & -0.40 & 0.02 & Nosema ceranae & 0.21 & 0.25 \\
\hline
\end{tabular}

† Values depect change overwinter in midguts of WW and CW samples. See Table S1 for a complete list of values.

* Enterobacteriaceae occurred with low frequency and abundance in cold winter samples. 


$\begin{array}{lllllll}\text { CAT } & \text { Bacterial Diversity } & 0.09 & 0.66 & \text { Bacterial Diversity } & -0.39 & 0.04\end{array}$

† Values depect change overwinter in midguts of WW and CW samples. See Table S1 for a complete list of values.

* Enterobacteriaceae occurred with low frequency and abundance in cold winter samples.

In the WW outdoor environment, HPG expression differed from early to late winter for two of seven genes (Table 1, Table S4). As a marker of nutritional state, vitellogenin expression decreased significantly overwinter, while Abaecin expression increased. Vitellogenin expression was negatively correlated with late winter increases of bacterial diversity, bacterial diversity abundance, and fungal abundance (Table 3). Abaecin expression was negatively associated with Xanthomonadaceae abundance in the midgut overwinter, but positively associated with Enterobacteriaceae (Table 3). Hymenoptacin and Defensin-1 expression decreased markedly, but not significantly from early to late winter (Table S4). Both were negatively correlated with the midgut increase in Nosema ceranae abundance (Table 3). Hymenoptacin expression was negatively correlated with bacterial diversity, fungal abundance and Actinomycetales (Table 3). Oxidative state interactions associated with the WW microbiota were limited to Nosema ceranae and bacterial diversity, which became more abundant in late winter midguts concurrent with a significant decrease in GOX expression (Tables S1, S4).

\section{Discussion}

We describe a novel relationship in Apis mellifera involving the colony microbiota, the hindgut microbiota, and social gene expression. We suggest that the hypopharyngeal gland (HPG) performs a vital defense role in overwintering honey bees, on par with its established role in providing shared nutrition for colony members during periods of growth. More specifically, in diutinus workers, the abundance of the five corehindgut bacteria were positively inter-correlated on the mouth and in the midgut throughout the aging process, showing strong age-related associations with the expression of HPG secreted antimicrobial peptides (AMPs), the redox enzyme glucose oxidase (GOX), and superoxide dismutase; $\mathrm{Cu} / \mathrm{ZnSOD}$ and MnSOD (Table 1). We hypothesize that this gene expression may occur across many tissues, and represents a more generalized metabolic state of diutinus bees associated with aging and resistance to opportunism. Our results are similar to host microbial control seen in other social insect species including host secretions that nurture defensive symbionts $[2,6,70,93]$. The results suggest one mechanistic hypothesis for the lack of antimicrobial peptides in the honey bee genome [94]. Much of the microbial variation and abundance in the gut and colony environment may be mitigated by the redox potential of the individual and the colony $[1,27]$.

In honey bees and other organisms, microbiota and associated disease states have evolved to exploit social context and distinct developmental and reproductive phenotypes $[13,32,33,66]$. The microbiome of the worker mouth, social stomach, and midgut highlight the intimate connectedness of colony members via hygienic behavior and trophallaxis within the colony (food and information sharing). These 
resource-laden niches provide a window into disease transmission, as compositional (dysbiotic) changes in these microbiotas are strongly correlated with host health and the colony microbiota [14]. The foregut (crop or social stomach) is a non-digestive expandable bag located between the mouth and midgut, used to share honey and jelly provisions with other colony members. Due to rapid shifts in osmolarity, redox potential, $\mathrm{pH}$, and antimicrobial character, it is considered a harsh microbial environment [22]. In the foregut, we typically detect gram-positive core hindgut bacteria, Enterobacteriaceae, Lactobacillus kunkeei and Parasaccharibacter apium, but few others (Fig. 7). The microbial load of the foregut is low relative to the midgut and hindgut, but varies in size and diversity by worker task consistent with an antibiotic effect during nectar dehydration, and significantly greater microbial diversity and abundance in foragers[30]. In this study, the colony microbiota was evident in the midguts of $\mathrm{CW}$ samples, and on the mouthparts of aging diutinus (KA) workers typified by the occurrence of P. apium, L. kunkeei, Xanthomonadaceae, Actinomycetales, Comamonadaceae, and Enterobacteriaceae (Figs. 3, 5 and 7). These microbiotas are overtly similar to those described from the worker HPG and fresh royal jelly [14, 18], suggesting that the HPG is a continuous microbial niche that secretes the hindgut and colony microbiota in addition to nutrition, enzymes, and antimicrobial peptides. Regardless, these patterns indicate that HPG secretions played a prominent role in shaping the microbiotas of the mouth and midgut overwinter.

Our findings for the mouth and midgut are consistent with those presented in a companion paper that deep sequenced the ileum and rectum microbiotas from the same three (KA, CW, WW) sample sets presented here [8]. Considered collectively, the midguts of late winter bees in southern AZ were dysbiotic independent of age while the ileum and rectum (hindgut) microbiota remained largely undisturbed. Similarly, disruption of the midgut by Nosema ceranae infection does not necessarily result in large compositional changes to the hindgut microbiota [95]. However, it is clear from these and other results that distinct and disparate gut niches are altered synchronously by opportunism or perturbation [14]. Fungal abundance and bacterial diversity decreased significantly and collectively on the mouthparts, ileums and rectums of aging diutinus bees [8], (Fig. 4), and showed a strong negative association with the expression of GOX and both SOD genes from the HPG (Table 2). Resulting gene expression relative to the general character and taxonomy of all four alimentary tract niches suggests a systemic hostmicrobial interaction that functions throughout the entire alimentary tract. In support of this hypothesis, the hindgut microbiota in conventionalized bees is associated with significantly lower $\mathrm{pH}$ and redox potential throughout the entire gut [27].

\section{The Redox Environment / ROS Gene Expression}

Our results show that host responses to microbial opportunism involve antimicrobial peptides, and ROS associated gene expression (Table 1). Produced in response to social role, glucose oxidase (GOX) is omnipresent throughout social resource space, and is considered an immediate form of social immune response [61]. GOX functions as a pro-oxidant (generates reactive oxygen species; ROS) that thwarts microbial growth by converting omnipresent glucose into hydrogen peroxide and gluconic acid throughout the colony niche. ROS interfere with gram-negative iron metabolism, but gram-positive 
species are more resilient [96]. This function is consistent with the occurrence and abundance of core hindgut species in the hive and colony environment. Of the core hindgut species, Snodgrassella alvi is least abundant throughout the social/hive environment [13], perhaps a result of ROS social dynamics. In general however, bacteria that have evolved with the gut environment appear resilient to GOX expression. The abundance of all five core-hindgut bacteria in the midgut were positively associated with the expression of GOX in the HPG highlighting a fundamental host-microbial relationship[27] that likely facilitates hindgut microbiome survival/establishment and limits opportunism (Table 2, Table S4). The concurrent upregulation of Vitellogenin (Vg), GOX, AMPs and SODs in the HPG is consistent with the aging diutinus host response to a microbially challenging overwintering environment (Table 1). Vitellogenin is an antioxidant [97], and superoxide dismutase (MnSOD, and CuZnSOD) are able to scavenge excess oxidants associated with metabolic demand or microbial challenge and convert them into less harmful molecules [98]. Of these two, only CuZnSOD is secreted by the HPG [99], while increased expression of MnSOD is an indication of increased mitochondrial function (Table 1).

In the southern overwintering environment, immune response in late winter differed between old and young bees, and the pattern of gene expression indicates that GOX and SOD secretion is metabolically expensive (Table 1, Table S4). Older diutinus bees had a strong immune response and low levels of fungal infection and bacterial diversity, while younger bees appeared less resistant to infection. Similar to the occurrence patterns of Enterobacteriaceae in WW and KA samples, older bees challenged with the midgut parasite Nosema developed more severe infections than younger bees, but survived infection better [100]. This is consistent with our findings wherein the longer-lived diutinus bees possessed the molecular resources (e.g. Vitellogenin) to combat infection. The hypothesis of poor larval nutrition overwinter is consistent with the expression patterns of $\mathrm{Vg}$ and other secreted gene products from the HPG across treatments [74]. While Vg expression in the HPG is unstudied, the overall expression patterns suggest that $\mathrm{Vg}$ expressed in the HPG may reflect a general nutritional state throughout the host organism. Vitellogenin is expressed in the midgut perhaps in response to opportunistic bacteria and fungi [101]. In older diutinus bees, $\mathrm{Vg}$ expression was positively associated with SOD expression suggesting the resources were available to mount an immune response (Table 1). In turn, the expression of both SOD genes was strongly associated with GOX production. In contrast, $\mathrm{Vg}$ expression in younger (WW) bees decreased significantly overwinter (Table 1, Table S4) and was negatively associated with increases in bacterial diversity and diversity abundance (Table 3, Table S1), suggesting that scarce resources were available to combat opportunism in this cohort. The indoor CW colonies showed no strong associations with $\mathrm{Vg}$ expression overwinter and no immune response, indicative of energy conservation and no microbial challenge. Although queen and queen-like (diutinus) phenotypes often possess higher mean ROS than workers in the form of $\mathrm{H}_{2} \mathrm{O}_{2}$, similar levels of fat body protein carboxylation between castes are maintained because queens or queen-like phenotypes can afford to mount an immune response, expressing antioxidant genes that include MnSOD and CuZnSOD [102]. There may be a similar explanation for the different response to opportunism between 50-70 day old (KA) workers and workers $>30$ days-old (WW) sampled in late winter. The younger (WW) bees that emerged during winter lacked the resources to mount an immune response [103], producing very different host-microbial interactions.

Page $21 / 44$ 
GOX expression overwinter appears critical to colony health; it increased significantly with age in the diutinus (KA) samples, remained unchanged overwinter in the WW samples, and decreased significantly overwinter in the $\mathrm{CW}$ samples (Table 1). The resulting host-microbial correlates by sample set suggest a fundamental ecological interpretation associated with the control of ROS in the colony and gut overwinter. To review, an obligate aerobe, $S$. alvi, is partnered with the metabolism of $G$. apicola in the ileum of a healthy worker host, contributing to the production of an anoxic hindgut environment [27]. We hypothesize that oxidative control of the midgut is associated with the increased abundance and structure of the core hindgut phylotypes in the midgut, as modeled for the ileum microbiota [27]. In the cold indoor environment, GOX expression decreased, while the abundance of core hindgut bacteria $S$. alvi, G. apicola and B. asteroides increased significantly. In fact, all five of the core hindgut bacteria increased as a correlated group in the CW midgut, while less abundant OTUs, and bacterial diversity decreased (Table S1, Figs. 2 and 5). The core five hindgut bacteria are well equipped to exploit low oxygen gut environments and many strains are capable of producing their own catalase and SOD [104, 105]. Several commensal bacteria, like Lactobacillus species secrete ROS into their surroundings, and this activity influences the growth of other commensal organisms including fungi. In the warm southern outdoors, GOX and SOD expression in the HPG of older diutinus workers (KA samples) increased significantly overwinter, associated with a reduction of fungi and bacterial diversity on the mouthparts (Table 2). In the late WW samples, comprised mostly of middle-aged bees born during the winter, GOX production was unchanged, concurrent with significant increases in Nosema ceranae, bacterial diversity and fungal abundance (Table 3). Again, the collective results indicate that CW colonies possessed low fungal abundance and a healthy microbiota and did not require an immune response. In contrast, WW colonies were dysbiotic, but could not afford to mount a strong immune response, while long-lived diutinus (KA) bees had the nutritional resources to mount an immune response to bacterial and fungal opportunism (Table 1).

\section{AMP Expression in the HPG}

Antimicrobial peptides were expressed differentially in the HPG by age and overwintering environment (Table 1). Although hymenoptacin and abecin are active against a variety of gram negative and enteric pathogens including Enterobacteriaceae [106], their expression in the HPG was unassociated with the majority of bacteria in the midgut or on the mouth of diutinus bees (Table S1). Most notably, none of the core-five hindgut bacteria were significantly associated with AMP expression, consistent with their longterm co-evolution with secreted honey bee defensive peptides (Table S1). However, social immune gene expression is costly and likely associated with careful regulation [61]. Both abecin and hymenoptacin were upregulated with age in diutinus bees (Table 1). We recorded a significant reduction in Xanthomonadaceae bacteria on the mouthparts of diutinus bees expressing significantly more antimicrobial peptides from their hypopharengeal glands (Table 1, Fig. 3). Abaecin is highly effective against Xanthomonas campestris, a well-known plant pathogen [107]. Aging diutinus bees showed a significant reduction in the absolute and relative abundance of midgut Xanthomonadaceae, and a relative decrease in Xanthomonadaceae in the ileum and rectum [8]. The same Xanthomonadaceae OTU is prevalent and abundant in the microbiota of the HPG and jelly according to two studies $[14,18]$. This 
indicates a targeted host response to a colony opportunist but requires further study. Concurrent with increased upregulation of GOX, SOD, abaecin and hymenoptacin in older diutinus bees, the abundance of Xanthomonadaceae (an aerobe), fungal load, and bacterial diversity all decreased significantly on the mouthparts (Fig. 3, Table S2). Under the same conditions, Actinomycetales (an anaerobe) became significantly more abundant on the mouthparts. Actinomycetes are well known for antibiotic richness, and the suppression of fungal growth [108]. There is a wide variety of native and relatively unknown Actinobacteria in the social environment of honey bee colonies [22]. The associations of this particular Actinobacterial OTU with host-microbial metrics differed by sample set and niche, suggesting it is an influential member of the colony microbiota with a close association to colony fungi (Tables 2 and 3 ).

\section{Cold indoor colonies overwinter}

Cold indoor overwintering is a highly successful technique proven over many generations of beekeeping experience $[74,79]$. It keeps the workers of the colony from flying or performing activities associated with brood rearing like larval nursing and pollen collection, behaviors that lead to metabolically expensive oxidative states that vary in severity by tissue, and contribute to early senescence $[109,110]$. Cold indoor overwintering also disrupts the cycle of the ectoparasitic Varroa mite, associated with viral transmission, host immune suppression and oxidative damage [111, 112]. That the gut microbiome of CW bees did not shift overwinter suggests that the diutinus physiology of energy conservation is associated with microbiome stasis.

To effectively compare southern (KA and WW samples) to northern overwintering (CW samples), we briefly review the microbiota and general health of $\mathrm{CW}$ colonies overwintered indoors at $7^{\circ} \mathrm{C}$. As a comparative example, all CW colonies overwintered successfully, and showed a broad collection of factors that distinguish them from the warm winter apiary. Our results for $\mathrm{CW}$ conditions indicate that we effectively sampled the early and late diutinus phenotype. The change overwinter was associated with gut microbial stasis, energy conservation, and a lack of microbial opportunism. The hindgut microbiota, intimately tied to host metabolism [27], was either improved overwinter or not diminished (Fig. 5), [8]. The whole gut microbiota (midgut, ileum, rectum) did not change in size, and retained its structure. Fungi remained low and constant overwinter throughout the entire alimentary tract, in the midgut, ileum and rectum (Fig. 6), [8]. Bacterial diversity throughout the gut decreased drastically (Fig. 2). Immune related HPG gene expression either did not differ, or decreased from early to late winter. The expression of genes associated with oxidative stress and microbial control remained constant in the HPG; both defensin-1 and GOX production decreased significantly overwinter consistent with a stable hive environment (Table 1); similar to other findings from healthy hives kept in cold winter conditions [113]. The abundance of Nosema ceranae, a destructive midgut parasite, also remained low and constant in the midgut overwinter (Table S3). The same Enterobacteriaceae and Gilliamella spp. found in dysbiotic WW samples were detected in CW samples, but at negligible prevalence and abundance, decreasing overwinter in the worker hindgut [8].

\section{Comparing warm to cold winter environments}


To provide context for the comparison of $\mathrm{CW}$ to WW overwintering environments, we reference the estimated age structure associated with the diutinus (KA) marked cohort. The outdoor overwintering environments experienced by KA and WW bees were highly similar, in southern AZ, subject to diurnal cycles and access to the pollination environment. However, the sampling associated with WW colonies was random with respect to age, while KA sampling was both age and time-specific. The collection of 19/33 day-old bees in early/mid-winter likely sampled many foragers, and some destined to live a longer "diutinus" life. Consistent with foraging behavior [13] the 19/33 day-old bees contained significantly more Gilliamella apicola and Gilliamella spp. compared to randomly collected in-hive bees from the same environment. The $50 / 70$ day old bees sampled in mid-late winter were clearly diutinus bees expressing HPG enzymes associated with plentiful storage proteins [74], and microbial challenge. Independent of age, the midguts of both KA and WW treatment groups in late winter were overgrown with Enterobacteriaceae and Gilliamella spp. (Figs. 3 and 5). However, host immune gene expression and fungal abundance differed significantly between KA and WW samples. The mouthparts of diutinus (KA) bees showed a significant reduction in fungal load with age (Fig. 3), and this pattern was repeated in the hindgut (ileums and rectums) of these same bees [8]. In contrast, fungal load increased significantly overwinter in the midguts of randomly sampled WW bees (Fig. 6), concurrent with significant fungal increases recorded for the ileum and rectum [8]. Based on these results we suggest that longevityassociated (diutinus) physiology and associated HPG gene expression suppresses fungal growth and bacterial diversity throughout the entirety of the diutinus worker alimentary tract.

According to rough estimates from Maes et al.[8] the average age of workers in the WW colonies was $<30$ days of age, and less than $10 \%$ of introduced workers in the KA cohort lived $>50$ days. The younger bees that emerged during the winter in southern climates may have lacked the nutritional resources needed to produce the diutinus phenotype, although we did not control for nutrition. A question that emerges from our results would explore how conflicting proximal cues may affect colony division of labor under warm winter conditions. In the same colony, do particular genotypes nurse and forage while others enter the diutinus state? Our experiment would have benefitted by classifying the physiology and social role of diutinus bees and randomly collected cohorts, including what they had consumed and when, whether they were primarily nursing or foraging, and levels of storage proteins. It is also possible that variation in colony size, demography, and hive structure between KA and WW samples affected these results. In general, however, our results indicate greater microbial exposure and less microbial control in the warm outdoor environment (Fig. 2). The stark difference between CW and WW samples in gut bacterial diversity, microbiota structure and fungal load overwinter may be associated with early winter nutrition and colony function $[73,74]$.

\section{Aging and opportunism in the midgut}

The collective information suggests that the midgut is a likely target for opportunistic fungi and bacteria overwinter in southern climates. Based on absolute abundance, Enterobacteriaceae was the dominant bacterium in the midgut of both outdoor southern experiments sampled in late winter regardless of age or host gene expression. Enterobacteriaceae are part of the colony microbiota (Fig. 7) and many are

Page 24/44 
associated with disease and overwintering [43]. In both the KA and WW samples, blooms of Enterobacteriaceae and an undescribed Gilliamella spp. dominated the midgut microbiota of many individuals and colonies (Figs. 3 and 5). The hindgut (both ileum and rectum) of these same KA and WW samples also experienced a significant increase of the same two OTUs, but they were $<1 \%$ of the hindgut microbiome cell count [8]. The abundance of these two putative opportunists was strongly intercorrelated (Rs $=0.78, p=0.0001)$, and both were strongly associated with significant overwintering increases of total fungi and bacterial diversity abundance throughout the entire gut[8]. The relationships of putative opportunists with host gene expression were similar to those for the pervasive midgut pathogen Nosema (Table S1) supporting the hypothesis of opportunism.

Our results suggest that the Enterobacteriaceae OTU detected by this study can survive at low abundance overwinter on the mouthparts of aging honey bees. It is readily transmitted, and present on $97 \%$ of worker mouthparts $>19$ days of age at $<1 \%$ average abundance (Table S2). From the same individuals with midgut infections, Enterobacteriaceae also established in the hindgut, but at very low relative abundance [8]. This scenario suggests that infection starts in the midgut where microbial competition is low, then spreads to the hemolymph and/or hindgut. Similar to the five core-hindgut phylotypes, the abundance of Enterobacteriaceae in the midgut was correlated positively with GOX and SOD gene expression but the same host-microbe relationship on the mouth was modestly negative, indicating that the mouth and associated HPG secretions may act as a first line of defense against invaders (Table 2). We hypothesize that most microbes from the mouth and midgut are part of the core colony microbiota having evolved physiology to counter ROS, and strategies to exploit the hive and social environment (Fig. 7). Larger mouthpart microbiomes are associated with $P$. apium, which multiplies rapidly in response to royal jelly or propolis exposure [4,32]. The queen mouth and midgut are exposed constantly to royal jelly, and are dominated by P. apium [33]. However, it seems that Enterobacteriaceae can evade honey bee defenses on the mouth and crop, then establish in the midgut (Figs. 3 and 7). Labeled the honey bee assassin [45], Serratia marcescens was abundant in the midguts of two 70-day-old worker bees. Like many other Enterobacteriaceae found in the colony environment, Serratia marsescens and Enterobacter spp. are chitinolytic[45], which may provide a growth advantage once they attain the midgut environment.

In early adult life, bacterial establishment in the midgut is low relative to the available surface area likely because midgut pollen digestion involves continuous shedding of peritrophic membrane from the epithelium creating an unstable microbial niche [114]. Following pollen digestion however, the production of peritrophic membrane slows or stops $[101,115]$, and it is unknown how the midgut regulates microbial growth with age. There is new evidence that the diutinus phenotype will continue to consume available pollen or artificial pollen substitutes overwinter (Randy Oliver pers. comm). The anterior midgut produces a peritrophic gel [116] that may be more vulnerable to opportunism than the posterior midgut, but this requires further study. The anterior midgut is significantly more acidic than the posterior midgut[27] favoring core hindgut bacteria. Our diutinus sample set began at day 19 , when it is likely that all bees of this age have transitioned from nursing to either foraging or a diutinus state. As diutinus bees aged, bacterial load remained stable on the mouthparts, increased significantly in the midgut, remained stable in the ileum, and decreased in the rectum (Fig. 4), [8] suggesting decreased pollen volume in the rectum, 
but we did not account directly for this variable. Regardless of age, we discovered that the midgut microbiota can be volatile in late winter harboring $10^{5}-10^{6}$ bacterial cells when healthy, but $10^{7}-10^{9}$ cells when dysbiotic (Fig. 6). These midgut microbiotas showed two general enterotypes; smaller microbiotas with somewhat even distributions of 5-9 OTUs and significantly larger microbiotas dominated by one or two OTUs. Collectively this suggests that the midgut of late winter bees may be more vulnerable to microbial opportunism following a transition in midgut physiology, and if not countered by host gene expression, bacterial and fungal opportunism may contribute to premature senescence of workers and colonies.

\section{Conclusion/perspective}

The evolution of the gut microbiome in corbiculate bees tracks social evolution [117], and the shift to a perennial lifestyle has refined the function of both hindgut and colony microbiota. Our findings for diutinus bees, microbiota and overwintering survival provides a novel perspective on health and disease in the social group context. Climate controlled indoor wintering was remarkably stable according to our metrics, suggesting that all sampled worker bees had effectively transitioned to the diutinus phenotype. In contrast, colonies kept outdoors in southern environments suffered dysbiosis that proliferates in the midgut. Workers born during the winter in southern environments were susceptible to opportunism, while workers funded by fall nutrition were expressing the diutinus phenotype (queen-like physiology) to some degree to finance an environment of individual and social immunity $[102,118,119]$. At the colony level, the cost/benefit ratio associated with this phenotypic expression may be a major factor in overwintering survival.

There are many potential explanations for the host-microbial interactions presented here (Table 1, Table S1). We have provided one parsimonious perspective evoking colony dynamics in response to environmental conditions. Our hypothesis of colony-microbiome interaction is supported by demonstrated host behavior and physiology $[56,119,120]$ and a growing understanding of beneficial, opportunistic and pathogenic honey bee microbes in the gut and colony environment $[7,13,121]$. We note that host niches and associated microbiotas are far more complex than discussed, and that the confirmation of a core colony microbiota will require further iteration and experimentation. Given the variety of social behaviors and microbes throughout the social environment [122], the behavioral and physiological processes associated with microbial odors or microbe-associated molecular patterns is an open question [68]. Hygienic worker behavior is presently defined by response to death-associated larval odors, and removal behavior by adult workers $[123,124]$. A few large loci were associated with recognizing and removing dead larvae according to quantitative trait loci analysis[125]. More recent work suggests the involvement 73 candidate genes, many under positive selection, consistent with rapidly evolving complex social behavior mitigating the colony microbiome [126].

While the honey bee is a generalist pollinator, it is a specialist at controlling microbial growth, often considered a distinguishing characteristic of sociality $[4,18,32,70,127]$. Opportunistic (noncommunicable) disease states in honey bees remain a mystery, but the tendency for diseased individuals 
to leave the hive in self-sacrifice may be an indication of their socially adaptive significance [128]. The relationship of colony and gut microbiota with both individual and social immune function highlights the range of host-microbial interaction associated with the superorganismal honey bee microbiota, and its potential influence on colony health, disease resistance and gut integrity [121]. While selection for the holobiont is considered weak in most organisms, highly cohesive host-microbial systems with strong group selection, overlapping generations, reliable resource abundance and built colony structures might better fit the criteria of a holobiont $[1,2,121,129-131]$.

\section{Abbreviations}

WW: Warm Winter; CW: Cold Winter; KA: Known Age; HPG: Hypopharyngeal Gland; GOX: Glucose Oxidase; $\mathrm{H}_{2} \mathrm{O}_{2}$ : Hydrogen Peroxide; ROS: Reactive Oxygen Species; Redox: Reduction /oxidation; MnSOD: Manganese Superoxide Dismutase; CuZnSOD: Copper-Zinc Superoxide Dismutase; AMPs: Antimicrobial Peptides; Vg: Vitellogenin; 16S rRNA gene: 16S subunit of the ribosomal RNA gene; AWK: Aho, Weinberger, Kernighan; SED: Stream editor; ANOVA: Analysis of variance; AZ: Arizona; BLAST: Basic local alignment search tool; bp: Base pairs; CLR: Centered log ratio; DNA: Deoxyribonucleic acid; FDR: False discovery rate; GLM: General linear models; MANOVA: Multivariate analysis of variance; OTU: Operational taxonomic unit; PCA: Principal components analysis; qPCR: Quantitative polymerase chain reaction; RDP: Ribosomal Database Project; rRNA: ribosomal ribonucleic acid.

\section{Declarations}

Ethics approval and consent to participate Not applicable.

Consent for publication Not applicable.

Availability of data and materials Next gene sequencing libraries of the mouth and midgut were deposited in GenBank under Sequence Read Archive (SRA) accession PRJNA742765. Associated with the same KA WW and CW sample sets, next gene sequencing libraries for the ileum and rectum were deposited in GenBank under Sequence Read Archive (SRA) accessions PRJNA705676 (WW and CW samples) and PRJNA705672 (KA samples).

Competing interests The authors declare no competing interests.

Funding Kirk E. Anderson was funded by the USDA-ARS, research plan 305 Anderson 2022-21000-02100D. The ARS is an equal opportunity employer and provider.

Authors' contributions KEA and PM conceived of and designed the research. PM contributed new analytical tools. KEA and PM performed the experiments. KEA and PM analyzed the data. KEA wrote the manuscript. All authors read and approved the final manuscript. 
Acknowledgements The authors thank Brendon Mott, Duan Copeland, Vincent Ricigliano, Jay Evans and Randy Oliver for their input.

\section{References}

1. Evans JD, Spivak M. Socialized medicine: Individual and communal disease barriers in honey bees. J Invertebr Pathol. 2010;103:S62--S72.

2. Hughes DP, Pierce NE, Boomsma JJ. Social insect symbionts: evolution in homeostatic fortresses. Trends Ecol Evol. 2008;23:672-7.

3. Simone M, Evans JD, Spivak M. Resin collection and social immunity in honey bees. Evolution. 2009;63:3016-22.

4. Dalenberg H, Maes P, Mott B, Anderson KE, Spivak M. Propolis envelope promotes beneficial bacteria in the honey bee (Apis mellifera) mouthpart microbiome. Insects. 2020;11:1-12.

5. Poulsen M, Bot AM, Nielsen MG, Boomsma JJ. Experimental evidence for the costs and hygienic significance of the antibiotic metapleural gland secretion in leaf-cutting ants. Behav Ecol Sociobiol. 2002;52:151-7.

6. Rosengaus RB, Traniello JFA, Lefebvre ML, Maxmen AB. Fungistatic activity of the sternal gland secretion of the dampwood termite Zootermopsis angusticollis. Insectes Soc. 2004;51:259-64.

7. Kwong WK, Moran NA. Gut microbial communities of social bees. Nat Rev Microbiol. 2016;14:374-84.

8. Maes PW, Floyd AS, Mott BM, Anderson KE. Overwintering honey bee colonies: Effect of worker age and climate on the hindgut microbiota. Insects. 2021;12:1-16.

9. Brown BP, Wernegreen JJ. Deep divergence and rapid evolutionary rates in gut-associated Acetobacteraceae of ants. BMC Microbiol. 2016;16:140.

10. Douglas AE. The microbial dimension in insect nutritional ecology. Funct Ecol. 2009;23:38-47.

11. Kešnerová L, Emery O, Troilo M, Liberti J, Erkosar B, Engel P. Gut microbiota structure differs between honeybees in winter and summer. ISME J. 2020;14:801-14.

12. Raymann K, Shaffer Z, Moran NA. Antibiotic exposure perturbs the gut microbiota and elevates mortality in honeybees. PLoS Biol. 2017;15:1-22.

13. Anderson KE, Ricigliano VA. Honey bee gut dysbiosis: a novel context of disease ecology. Curr Opin Insect Sci. 2017;22:125-32.

14. Maes PW, Rodrigues PAP, Oliver R, Mott BM, Anderson KE. Diet-related gut bacterial dysbiosis correlates with impaired development, increased mortality and Nosema disease in the honeybee (Apis 
mellifera). Mol Ecol. 2016;25:5439-50.

15. Miller DL, Smith EA, Newton ILG. A bacterial symbiont protects honey bees from fungal disease. mBIO. 2021; 12:e00503-21

16. Motta EVS, Raymann K, Moran NA. Glyphosate perturbs the gut microbiota of honey bees. Proc Natl Acad Sci USA. 2018;115:10305-10.

17. Grice EA, Segre JA. The skin microbiome. Nat Rev Microbiol. 2011;9:244-53.

18. Corby-Harris V, Snyder LA, Schwan MR, Maes P, McFrederick QS, Anderson KE. Origin and effect of Alpha 2.2 Acetobacteraceae in honey bee larvae and description of Parasaccharibacter apium gen. nov., sp. nov. Appl Environ Microbiol. 2014;80:7460-72.

19. Floyd AS, Mott BM, Maes P, Copeland DC, McFrederick QS, Anderson KE. Microbial ecology of european foul brood disease in the honey bee (Apis mellifera): Towards a microbiome understanding of disease susceptibility. Insects. 2020;11:1-16.

20. Martinson VG, Danforth BN, Minckley RL, Rueppell O, Tingek S, Moran NA. A simple and distinctive microbiota associated with honey bees and bumble bees. Mol Ecol. 2011;20:619-28.

21. Sabree ZL, Hansen AK, Moran NA. Independent Studies Using Deep Sequencing Resolve the Same Set of Core Bacterial Species Dominating Gut Communities of Honey Bees. PLoS One. 2012;7:e41250.

22. Anderson KE, Sheehan TH, Mott BM, Maes P, Snyder L, Schwan MR, et al. Microbial ecology of the hive and pollination landscape: bacterial associates from floral nectar, the alimentary tract and stored food of honey bees (Apis mellifera). PLoS One. 2013;8:e83125.

23. Rokop ZP, Horton MA, Newton ILG. Interactions between cooccurring lactic acid bacteria in honey bee hives. Appl Environ Microbiol. 2015;81:7261-70.

24. Cox-foster DL, Conlan S, Holmes EC, Palacios G, Evans JD, Moran NA, et al. A metagenomic survey of microbes in honey bee colony collapse disorder. Science. 2007;318:283-7.

25. Anderson KE, Rodrigues PAP, Mott BM, Maes P, Corby-Harris V. Ecological Succession in the Honey Bee Gut: Shift in Lactobacillus Strain Dominance During Early Adult Development. Microb Ecol. 2016;71:1008-19.

26. Powell JE, Martinson VG, Urban-Mead K, Moran N a. Routes of Acquisition of the Gut Microbiota of the Honey Bee Apis mellifera. Appl Environ Microbiol. 2014;80:7378-87.

27. Zheng H, Powell JE, Steele MI, Dietrich C, Moran NA. Honeybee gut microbiota promotes host weight gain via bacterial metabolism and hormonal signaling. Proc Natl Acad Sci USA. 2017;114:4775-80. 
28. Anderson KE, Carroll MJ, Sheehan TIM, Mott BM. Hive-stored pollen of honey bees: many lines of evidence are consistent with pollen preservation, not nutrient conversion. Mol Ecol. 2014;23: 5904-5917.

29. Ludvigsen J, Rangberg A, Avershina E, Sekelja M, Kreibich C, Amdam G, et al. Shifts in the midgut/pyloric microbiota composition within a honey bee apiary throughout a season. Microbes Environ. 2015;30:235-44.

30. Corby-Harris V, Maes P, Anderson KE. The bacterial communities associated with honey bee (Apis mellifera) foragers. PLoS One. 2014;9:e95056.

31. Hölldobler B, Wilson EO. The Superorganism: The Beauty, Elegance, and Strangeness of Insect Societies. W.W. Norton \& Company; 2008.

32. Vojvodic S, Rehan SM, Anderson KE. Microbial Gut Diversity of Africanized and European Honey Bee Larval Instars. PLoS One. 2013;8:e72106.

33. Anderson KE, Ricigliano VA, Mott BM, Copeland DC, Floyd AS, Maes P. The Queen Gut Refines with Age: Longevity Phenotypes in a Social Insect Model. Microbiome; 2018;6:108

34. Cornman RS, Tarpy DR, Chen Y, Jeffreys L, Lopez D, Pettis JS, et al. Pathogen webs in collapsing honey bee colonies. PLoS One. 2012;7:e43562.

35. Djukic M, Poehlein A, Straub J, Tann FJ, Leimbach A, Hoppert M, et al. High quality draft genome of Lactobacillus kunkeei EFB6, isolated from a German European foulbrood outbreak of honeybees. Stand Genomic Sci. 2015;10:1-9.

36. Endo A, Futagawa-Endo Y, Dicks LMT. Isolation and characterization of fructophilic lactic acid bacteria from fructose-rich niches. Syst Appl Microbiol. 2009;32:593-600.

37. Snowdon JA, Cliver DO. Microorganisms in honey. Int J Food Microbiol. 1996;31:1-26.

38. Kacániová M, Chlebo R, Kopernický M, Trakovická a. Microflora of the honeybee gastrointestinal tract. Folia Microbiol. 2004;49:169-71.

39. Budge GE, Adams I, Thwaites R, Pietravalle S, Drew GC, Hurst GDD, et al. Identifying bacterial predictors of honey bee health. J Invertebr Pathol. 2016;141:41-4.

40. Evans JD, Armstrong T-N. Antagonistic interactions between honey bee bacterial symbionts and implications for disease. BMC Ecol. 2006;6:4.

41. Anderson KE, Sheehan TH, Eckholm BJ, Mott BM, DeGrandi-Hoffman G. An emerging paradigm of colony health: microbial balance of the honey bee and hive (Apis mellifera). Insectes Soc. 2011;58:43144. 
42. Gilliam M. Identification and roles of non-pathogenic microflora associated with honey bees. FEMS Microbiol Lett. 1997;155:1-10.

43. Lyapunov YE, Kuzyaev RZ, Khismatullin RG, Bezgodova OA. Intestinal enterobacteria of the hibernating Apis mellifera mellifera L. bees. Microbiology. 2008;77:373-9.

44. Welch DBM, Huse SM. Microbial Diversity in the Deep Sea and the Underexplored "Rare Biosphere." Handb Mol Microb Ecol II Metagenomics Differ Habitats. 2011;243-52.

45. Burritt NL, Foss NJ, Neeno-Eckwall EC, Church JO, Hilger AM, Hildebrand JA, et al. Sepsis and hemocyte loss in honey bees (Apis mellifera) infected with Serratia marcescens strain sicaria. PLoS One. 2016;11:1-26.

46. Disayathanoowat T, Young JPW, Helgason T, Chantawannakul P. T-RFLP analysis of bacterial communities in the midguts of Apis mellifera and Apis cerana honey bees in Thailand. Fems Micriobiology Ecol. 2011;79:273-81.

47. Gilliam M, Valentine DK. Enterobacteriaceae isolated from foraging worker honey bees, Apis mellifera. J Invertebr Pathol. 1974;23:38-41.

48. McFrederick QS, Wcislo WT, Taylor DR, Ishak HD, Dowd SE, Mueller UG. Environment or kin: whence do bees obtain acidophilic bacteria? Mol Ecol. 2012;21:1754-68.

49. Endo A, Salminen S. Honeybees and beehives are rich sources for fructophilic lactic acid bacteria. Syst Appl Microbiol. 2013;36:444-8.

50. Li L, Praet J, Borremans W, Nunes OC, Manaia CM, Cleenwerck I, et al. Bombella intestini gen. nov., sp. nov., an acetic acid bacterium isolated from bumble bee crop. Int J Syst Evol Microbiol. 2015;65:267-73.

51. Smith EA, Newton ILG. Genomic signatures of honey bee association in an acetic acid symbiont. Genome Biol Evol. 2020;12:1882-94.

52. Corby-Harris V, Snyder L, Meador CAD, Naldo R, Mott B, Anderson KE. Parasaccharibacter apium, gen. Nov., sp. Nov., Improves Honey Bee (Hymenoptera: Apidae) resistance to Nosema. J Econ Entomol. 2016;109:537-43.

53. Olaitan PB, Adeleke OE. Honey: a reservoir for microorganisms and an inhibitory agent for microbes. Afr Health Sci. 2007;7:159-65.

54. Ruiz-Argueso T, Rodriguez-Navarro A. Microbiology of ripening honey. Appl Microbiol. 1975;30:8936.

55. Münch D, Kreibich CD, Amdam GV. Aging and its modulation in a long-lived worker caste of the honey bee. J Exp Biol. 2013;216:1638-49. 
56. Amdam GV. Social context, stress, and plasticity of aging. Aging Cell. 2011;10:18-27.

57. Haddad LS, Kelbert L, Hulbert AJ. Extended longevity of queen honey bees compared to workers is associated with peroxidation-resistant membranes. Exp Gerontol. 2007;42:601-9.

58. Robinson GE, Page Jr RE, Strambi C, Strambi A. Hormonal and genetic control of behavioral integration in honey bees. Science 1989;264:109-12.

59. Amdam G V., Norberg K, Hagen A, Omholt SW. Social exploitation of vitellogenin. Proc Natl Acad Sci USA. 2003;100:1799-802.

60. Jones B, Shipley E, Arnold KE. Social immunity in honeybees-Density dependence, diet, and body mass trade-offs. Ecol Evol. 2018;8:4852-9.

61. Alaux C, Ducloz F, Crauser D, Le Conte Y. Diet effects on honeybee immunocompetence. Biol Lett. 2010;6:562-5.

62. Ohashi K, Natori S, Kubo T. Expression of amylase and glucose oxidase in the hypopharyngeal gland with an age-dependent role change of the worker honeybee (Apis mellifera L.). Eur J Biochem. 1999;265:127-33.

63. Vannette RL, Mohamed A, Johnson BR. Forager bees (Apis mellifera) highly express immune and detoxification genes in tissues associated with nectar processing. Sci Rep. 2015;5:16224

64. Ohashi K, Natori S, Kubo T. Change in the mode of gene expression of the hypopharyngeal gland cells with an age-dependent role change of the worker honeybee Apis mellifera L. Eur J Biochem.

1997;249:797-802.

65. Huang ZY, Robinson GE. Regulation of honey bee division of labor by colony age demography. Behav Ecol Sociobiol. 1996;39:147-58.

66. Vojvodic S, Johnson BR, Harpur BA, Kent CF, Zayed A, Anderson KE, et al. The transcriptomic and evolutionary signature of social interactions regulating honey bee caste development. Ecol Evol. 2015;5:4795-807.

67. Ohashi K, Sasaki M, Sasagawa H, Nakamura J, Natori S, Kubo T. Functional flexibility of the honey bee hypopharyngeal gland in a dequeened colony. Zoolog Sci. 2000;17:1089-94.

68. Harwood G, Salmela H, Freitak D, Amdam G. Social immunity in honey bees: royal jelly as a vehicle in transferring bacterial pathogen fragments between nestmates. J Exp Biol. 2021;224: jeb231076.

69. Santos KS, dos Santos LD, Mendes MA, de Souza BM, Malaspina O, Palma MS. Profiling the proteome complement of the secretion from hypopharyngeal gland of Africanized nurse-honeybees (Apis mellifera L.). Insect Biochem Mol Biol. 2005;35:85-91. 
70. Cremer S, Armitage SAO, Schmid-Hempel P. Social Immunity. Curr Biol. 2007;17:693-702.

71. Mattila HR, Otis GW. Dwindling pollen resources trigger the transition to broodless populations of long-lived honeybees each autumn. Ecol Entomol. 2007;32:496-505.

72. Crailsheim K, Riessberger U, Blaschon B, Nowogrodzki R, Hrassnigg N. Short-term effects of simulated bad weather conditions upon the behaviour of food-storer honeybees during day and night (Apis mellifera carnica Pollmann). Apidologie. 1999;30:299-310.

73. Ricigliano VA, Mott BM, Floyd AS, Copeland DC, Carroll MJ, Anderson KE. Honey bees overwintering in a southern climate: Longitudinal effects of nutrition and queen age on colony-level molecular physiology and performance. Sci Rep. 2018;8:1-11.

74. Ricigliano VA, Mott BM, Maes PW, Floyd AS, Fitz W, Copeland DC, et al. Honey bee colony performance and health are enhanced by apiary proximity to US Conservation Reserve Program (CRP) lands. Sci Rep. 2019;9:1-11.

75. Fukuda HSK. Seasonal change of the honey bee worker longevity in Sapporo, North Japan with notes on some factors affecting life span. Ecol Soc Japan. 1966;16:206-12.

76. Mattila HR, Harris JL, Otis GW. Timing of production of winter bees in honey bee (Apis mellifera) colonies. Insectes Soc. 2001;48:88-93.

77. Feliciano-Cardona S, Döke MA, Aleman J, Agosto-Rivera JL, Grozinger CM, Giray T. Honey Bees in the Tropics Show Winter Bee-Like Longevity in Response to Seasonal Dearth and Brood Reduction. Front Ecol Evol. 2020;8:1-8.

78. Döke MA, Frazier M, Grozinger CM. Overwintering honey bees: biology and management. Curr Opin Insect Sci. 2015;10:185-93.

79. Meikle WG, Weiss M, Maes PW, Fitz W, Snyder LA, Sheehan T, et al. Internal hive temperature as a means of monitoring honey bee colony health in a migratory beekeeping operation before and during winter. Apidologie. 2017;48:666-80.

80. Liu CM, Aziz M, Kachur S, Hsueh P-R, Huang Y-T, Keim P, et al. BactQuant: An enhanced broadcoverage bacterial quantitative real-time PCR assay. BMC Microbiol. 2012;12:56.

81. Liu CM, Kachur S, Dwan MG, Abraham AG, Aziz M, Hsueh PR, et al. FungiQuant: a broad-coverage fungal quantitative real-time PCR assay. BMC Microbiol. 2012;12:1.

82. Schloss PD, Westcott SL, Ryabin T, Hall JR, Hartmann M, Hollister EB, et al. Introducing mothur: opensource, platform-independent, community-supported software for describing and comparing microbial communities. Appl Environ Microbiol. 2009;75:7537-41. 
83. Pruesse E, Quast C, Knittel K, Fuchs BM, Ludwig W, Peplies J, et al. SILVA: a comprehensive online resource for quality checked and aligned ribosomal RNA sequence data compatible with ARB. Nucleic Acids Res. 2007;35:7188-96.

84. Edgar RC, Haas BJ, Clemente JC, Quince C, Knight R. UCHIME improves sensitivity and speed of chimera detection. Bioinformatics. 2011;27:2194-200.

85. Cole JR, Wang Q, Cardenas E, Fish J, Chai B, Farris RJ, et al. The Ribosomal Database Project: improved alignments and new tools for rRNA analysis. Nucleic Acids Res. 2009;37:D141--D145.

86. DeSantis TZ, Hugenholtz P, Larsen N. Greengenes, a chimera-checked 16S rRNA gene database and workbench. Appl Environ Microbiol. 2006;72: 5069-5072.

87. Evans JD. Beepath: An ordered quantitative-PCR array for exploring honey bee immunity and disease. J Invertebr Pathol. 2006;93:135-9.

88. Bourgeois AL, Rinderer TE, Beaman LD, Danka RG. Genetic detection and quantification of Nosema apis and N. ceranae in the honey bee. J Invertebr Pathol. 2010;103:53-8.

89. Pearson K. Mathematical Contributions to the Theory of Evolution.-On a Form of Spurious Correlation Which May Arise When Indices Are Used in the Measurement of Organs. Proc R Soc London. 1986;60:489-98.

90. Gloor GB, Reid G. Compositional analysis: a valid approach to analyze microbiome high throughput sequencing data. Can J Microbiol. 2016;62:692-703.

91. Comas M, Thio-Henestrosa S. CoDaPack 2.0: a stand-alone, multi-platform compositional software. In: Egozcue JJ, Tolosana-Delgado R, Ortego MI, Editors. 4th International Workshop on Compositional Data Analysis. 2011:1-10.

92. Větrovský T, Baldrian P. The Variability of the 16S rRNA Gene in Bacterial Genomes and Its Consequences for Bacterial Community Analyses. PLoS One. 2013;8:1-10.

93. Yek SH, Nash DR, Jensen AB, Boomsma JJ. Regulation and specificity of antifungal metapleural gland secretion in leaf-cutting ants. Proc Biol Sci. 2012;279:4215-22.

94. Evans JD, Aronstein K, Chen YP, Hetru C, Imler J-L, Jiang H, et al. Immune pathways and defence mechanisms in honey bees Apis mellifera. Insect Mol Biol. 2006;15:645-56.

95. Rubanov A, Russell KA, Rothman JA, Nieh JC, McFrederick QS. Intensity of Nosema ceranae infection is associated with specific honey bee gut bacteria and weakly associated with gut microbiome structure. Sci Rep. 2019;9:1-8. 
96. Wink DA, Hines HB, Cheng RYS, Switzer CH, Flores-Santana W, Vitek MP, et al. Nitric oxide and redox mechanisms in the immune response. J Leukoc Biol. 2011;89:873-91.

97. Seehuus S-CC, Norberg K, Gimsa U, Krekling T, Amdam G V. Reproductive protein protects functionally sterile honey bee workers from oxidative stress. Proc Natl Acad Sci USA. 2006;103:962-7.

98. Liu JR, Yang YC, Shi LS, Peng CC. Antioxidant properties of royal jelly associated with larval age and time of harvest. J Agric Food Chem. 2008;56:11447-52.

99. Li-E M, Jia L, Yan J, Xiao-Wen L, Xin L. Isolation, purification and characterization of superoxide dismutase from royal jelly of the Italian worker bee, Apis mellifera. Acta Entomol Sin. 2004;47:171-7.

100. Roberts KE, Hughes WOH. Immunosenescence and resistance to parasite infection in the honey bee, Apis mellifera. J Invertebr Pathol. 2014;121:1-6.

101. Harwood, Gyan H; Amdam G. Vitellogenin in the honey bee midgut. Apidologie; 2021; https://doi.org/10.1007/s13592-021-00869-3

102. Santos DE, Souza ADO, Tibério GJ, Alberici LC, Hartfelder K. Differential expression of antioxidant system genes in honey bee (Apis mellifera L .) caste development mitigates ROS-mediated oxidative damage in queen larvae. Genet Mol Biol. 2020;43: e20200173.

103. Li C, Xu B, Wang Y, Yang Z, Yang W. Protein content in larval diet affects adult longevity and antioxidant gene expression in honey bee workers. Entomol Exp Appl. 2014;151:19-26.

104. Bottacini F, Milani C, Turroni F, Sánchez B, Foroni E, Duranti S, et al. Bifidobacterium asteroides PRL2011 Genome Analysis Reveals Clues for Colonization of the Insect Gut. PLoS One. 2012;7:e44229.

105. Killer J, Dubná S, Sedláček I, Švec P. Lactobacillus apis sp. nov., from the stomach of honeybees (Apis mellifera), having an in vitro inhibitory effect on the causative agents of American and European foulbrood. Int J Syst Evol Microbiol. 2014;64:152-7.

106. Casteels P, Ampe C, Riviere L, van Damme J, Elicone C, Fleming M, et al. Isolation and characterization of abaecin, a major antibacterial response peptide in the honeybee (Apis mellifera). Eur $\mathrm{J}$ Biochem. 1990;187:381-6.

107. Casteels P, Ampe C, Jacobs F, Tempst P. Functional and chemical characterization of hymenoptaecin, an antibacterial polypeptide that is infection-inducible in the honeybee (Apis mellifera). $\mathrm{J}$ Biol Chem. 1993;268:7044-54.

108. Barke J, Seipke RF, Grüschow S, Heavens D, Drou N, Bibb MJ, et al. A mixed community of Actinomycetes produce multiple antibiotics for the fungus farming ant Acromyrmex octospinosus. BMC Biol. 2010;8:109. 
109. Aurori CM, Buttstedt A, Dezmirean DS, Mărghitaş LA, Moritz RFA a, Erler S. What is the main driver of ageing in long-lived winter honeybees: Antioxidant enzymes, innate immunity, or vitellogenin? Journals Gerontol - Ser A 2014;69:633-9.

110. Remolina SC, Hafez DM, Robinson GE, Hughes KA. Senescence in the worker honey bee Apis mellifera. J Insect Physiol. 2007;53:1027-33.

111. Rueppell O, Yousefi B, Collazo J, Smith D. Early life stress affects mortality rate more than social behavior, gene expression or oxidative damage in honey bee workers. Exp Gerontol. 2017;90:19-25.

112. Yang $X$, Cox-Foster DL. Impact of an ectoparasite on the immunity and pathology of an invertebrate: Evidence for host immunosuppression and viral amplification. Proc Natl Acad Sci USA. 2005;102:74705 .

113. Steinmann N, Corona M, Neumann P, Dainat B. Overwintering is associated with reduced expression of immune genes and higher susceptibility to virus infection in honey bees. PLoS One. 2015;10:1-18.

114. Crailsheim K. Regulation of food passage in the intestine of the honeybee (Apis mellifera L.). J Insect Physiol. 1988;34:85-90.

115. Jimenez DR, Gilliam M. Ultrastructure of the ventriculus of the honey bee, Apis mellifera (L.): cytochemical localization of acid phosphatase, alkaline phosphatase, and nonspecific esterase. Cell Tissue Res. 1990;261:431-43.

116. Terra WR, Bioquímica D De, Química I De, Paulo UDS, Paulo S. The Origin and Functions of the Insect Peritrophic Membrane and Peritrophic Gel. 2001;61:47-61.

117. Kwong WK, Medina LA, Koch H, Sing K-W, Jia E, Soh Y, et al. Dynamic microbiome evolution in social bees. Sci Adv. 2017;3:e1600513.

118. Corona M, Hughes KA, Weaver DB, Robinson GE. Gene expression patterns associated with queen honey bee longevity. Mech Ageing Dev. 2005;126:1230-8.

119. Corona M, Robinson GE. Genes of the antioxidant system of the honey bee: Annotation and phylogeny. 2006;15:687-701.

120. Crailsheim K, Hrassnigg N, Gmeinbauer R, Szolderits MJ, Schneider LHW. Pollen utilization in nonbreeding honeybees in winter $\mathrm{J}$ Insect Physiol.1993;39:369-373.

121. Schwarz RS, Huang Q, Evans JD. Hologenome theory and the honey bee pathosphere. Curr Opin Insect Sci. 2015;10:1-7.

122. Toth AL, Zayed A. The honey bee genome-what has it been good for? Apidologie; 2021;52:45-62. 
123. Swanson JA, Torto B, Kells SA, Mesce KA, Tumlinson JH, Spivak M. Odorants that induce hygienic behavior in honeybees: Identification of volatile compounds in chalkbrood-infected honeybee larvae. J Chem Ecol. 2009;35:1108-16.

124. Spivak M, Gilliam M. Facultative expression of hygienic behaviour of honey bees in relation to disease. 1993;32:147-57.

125. Lapidge KL, Oldroyd BP, Spivak M. Seven suggestive quantitative trait loci influence hygienic behavior of honey bees. Naturwissenschaften. 2002;89:565-8.

126. Harpur BA, Guarna MM, Huxter E, Higo H, Moon KM, Hoover SE, et al. Integrative Genomics Reveals the Genetics and Evolution of the Honey Bee's Social Immune System. Genome Biol Evol. 2019;11:93748.

127. Riessberger-Gallé U, Hernández López J, Schuehly W, Crockett S, Krainer S, Crailsheim K. Immune responses of honeybees and their fitness costs as compared to bumblebees. Apidologie. 2015;46:23849.

128. Rueppell O, Hayworth MK, Ross NP. Altruistic self-removal of health-compromised honey bee workers from their hive. J Evol Biol. 2010;23:1538-46.

129. Moran NA, Sloan DB. The Hologenome Concept: Helpful or Hollow? PLoS Biol. 2015;13:1-10.

130. Douglas AE, Werren JH. Holes in the hologenome: Why host-microbe symbioses are not holobionts. MBio. 2016;7:1-7.

131. Bordenstein SR, Theis KR. Host biology in light of the microbiome: Ten principles of holobionts and hologenomes. PLoS Biol. 2015;13:1-23.

\section{Figures}




\section{Experimental Design}

\section{Cold Indoor Wintering}

16 colonies/ $6+$ frames of bees Sampled in early/late winter

Random worker sampling

DV = Midgut microbiota

DV $=$ Social gene expression
Warm Outdoor Wintering

16 colonies $/ 6+$ frames of bees

Sampled in early/late winter

Random worker sampling

DV = Midgut microbiota

DV = Social gene expression
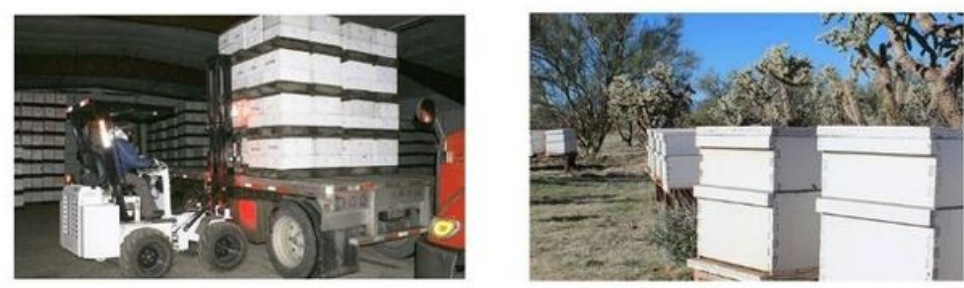

(CW)

Cold

Winter

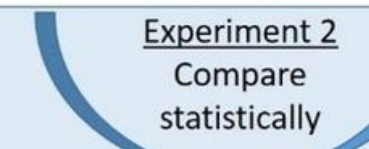

Experiment
Compare
statistically

Hyp. 1: Overwintering environment alters the microbiota Hyp. 2: Host social gene expression is associated with microbiota / overwintering environment
Warm Outdoor Wintering

Four observation hives in greenhouses

Targeted sampling of marked bees

Sampled workers aged $19,33,50$ and 70 days

$\mathrm{DV}=$ mouth and midgut microbiota

DV = Social gene expression: The secretion of

antimicrobial peptides and enzymes that control oxidative state

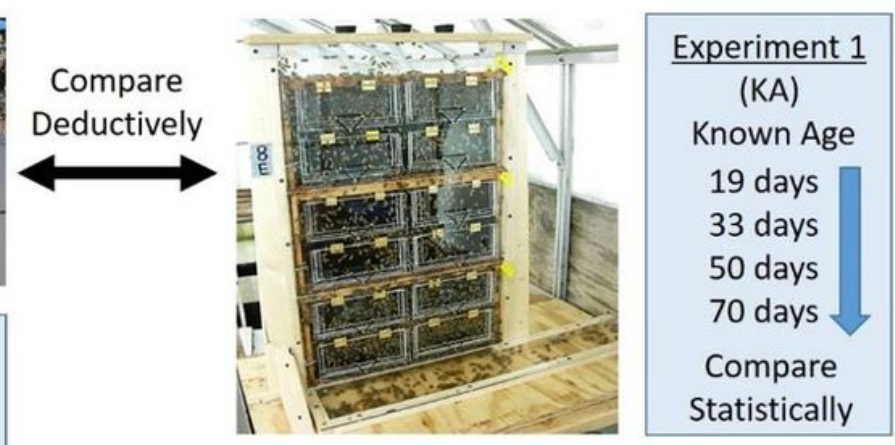

Hyp. 1: Colonies express the diutinus phenotype Hyp. 2: Aging workers maintain a stable microbiota Hyp. 3: Host social gene expression is associated with aging / character of mouth and midgut microbiota

\section{Figure 1}

Experimental design, sampling details and hypotheses. The blue boxes describe the manipulations performed in this study.

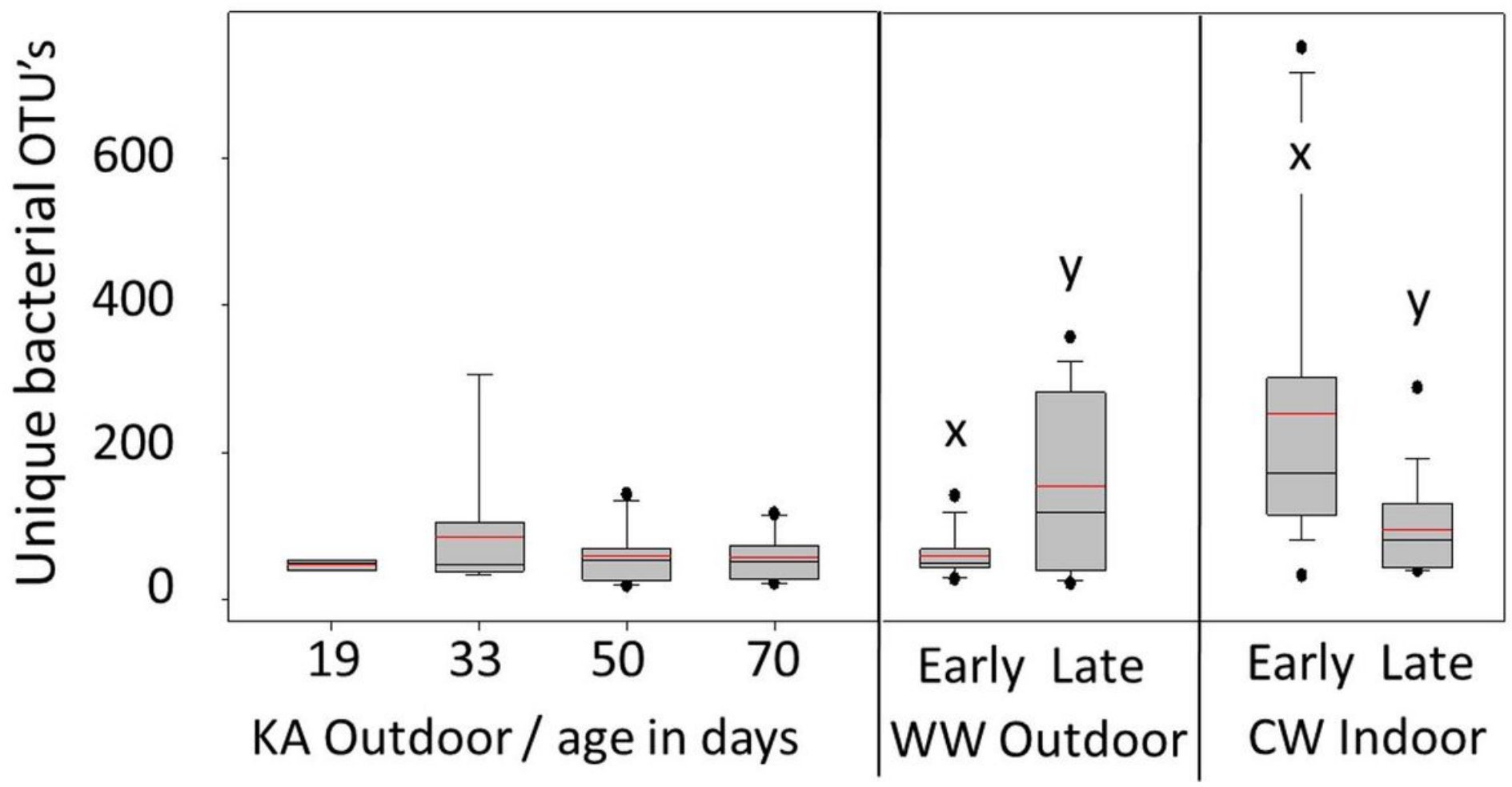




\section{Figure 2}

Bacterial diversity in midguts of overwintering bees depicted as the number of amplicon sequence variants or unique OTUs. Known age (KA) bees did not differ by age class overwinter. Diversity increased significantly in the warm winter (WW) outdoor environment $(\mathrm{t} 30=2.89, \mathrm{p}=0.007)$ and decreased significantly in the cold winter $(C W)$ indoor environment $(\mathrm{t} 32=2.89, \mathrm{p}=0.008)$. Grey boxes contain $75 \%$ of the variation, whiskers contain $90 \%$, and the dots are outliers. The horizontal red bar is the mean and black is the median.

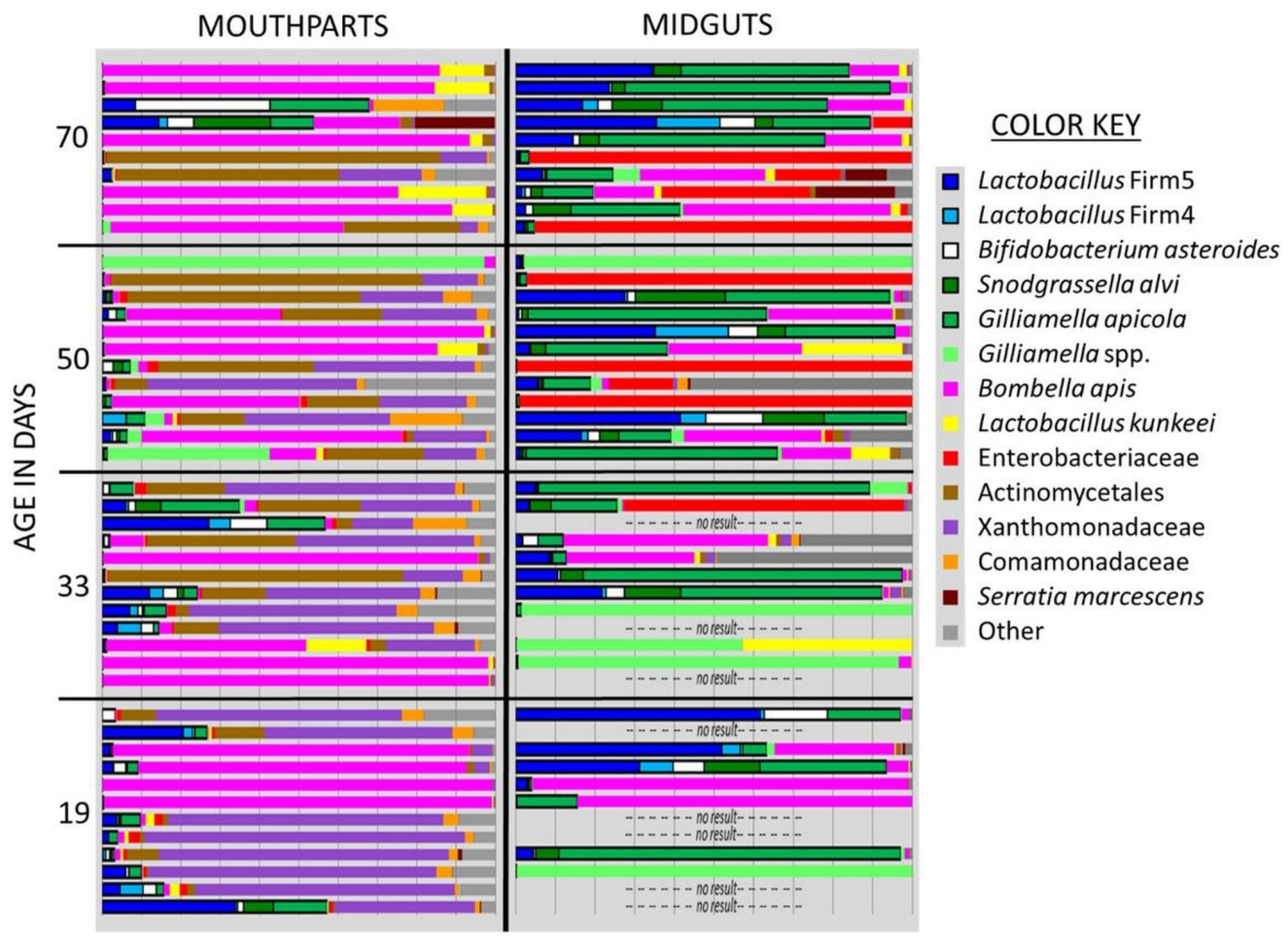

\section{Figure 3}

Relative OTU abundance for mouthpart and midgut microbiotas of diutinus worker bees overwintered in Tucson AZ, USA. The five core hindgut bacteria at the top of the key are outlined with a black border. Ages on the $y$-axis coincide with sampling dates; Newly emerged bees were marked and introduced to colonies in Early December, then sampled in late December at 19 days old, mid-January at 33 days old, late January at 50 Days old and mid-February at 70 days old. Significantly larger microbiotas are associated with P. apium (Pink) on the mouthparts, and Enterobacteriacae (Red) and Gilliamella spp. (GFP green) in the midgut. See Table S2 for absolute abundance. 

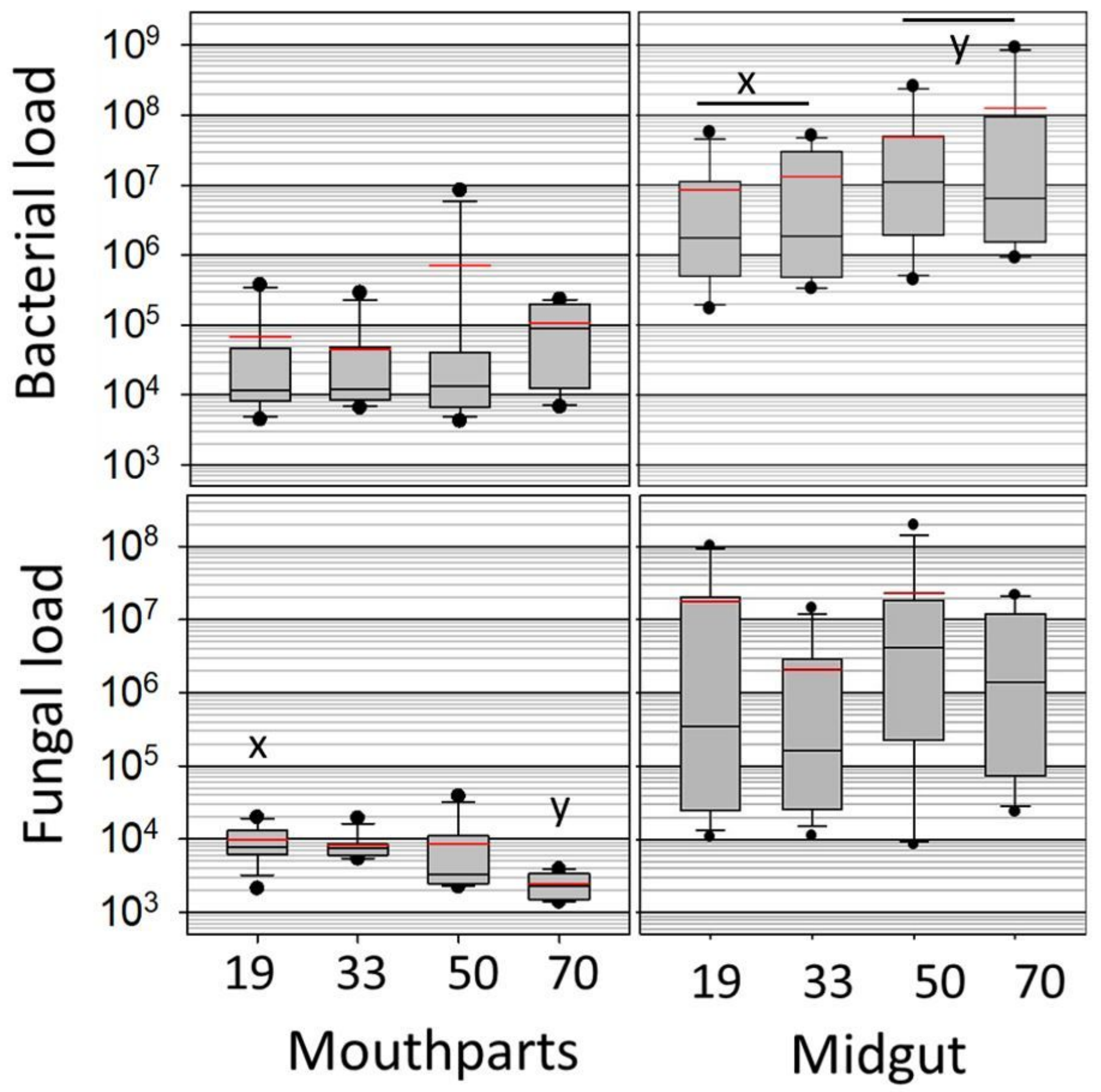

$\begin{array}{llll}19 & 33 & 50 & 70\end{array}$

Midgut

Figure 4

Change in microbial abundance on the mouthparts and in the midguts of diutinus worker bees. We collected known age KA samples at 19,33, 50 and 70 days of age from early December to mid-February in Tucson AZ, USA. Fungal load decreased with age in the mouthparts (W46 $=114, p=0.0004$ ), and bacterial load increased with age in the midguts (W38 $=166, p=0.03)$. The $y$-axis depicts mean $16 \mathrm{~S}$ copy number (bacterial load) and mean $18 \mathrm{~S}$ rRNA copy number (fungal load). Grey boxes contain $75 \%$ of the variation, whiskers contain $90 \%$, and the dots are outliers. The horizontal red bar is the mean and black is the median. Bacterial load corresponds to Figure 3. 


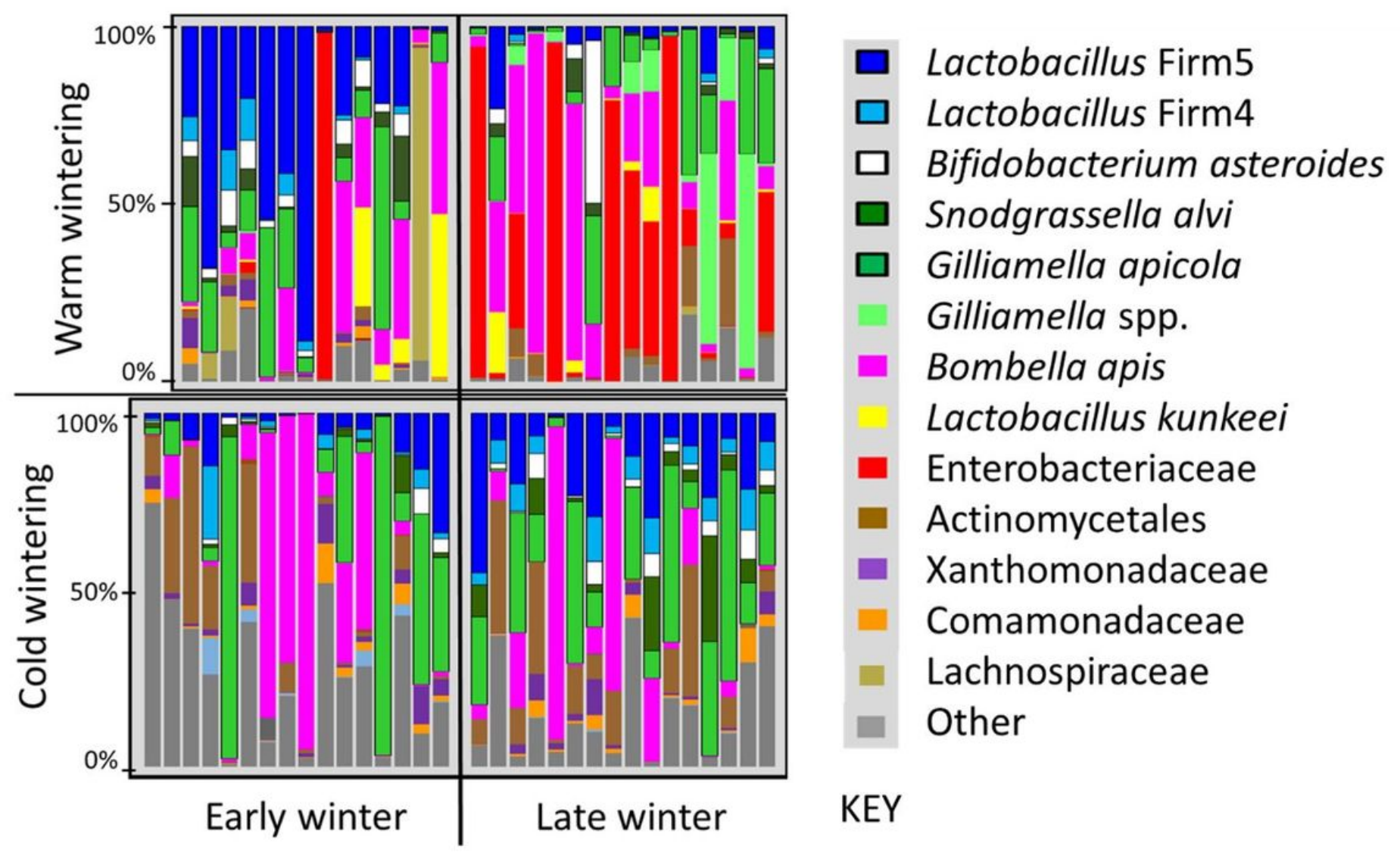

Figure 5

Relative abundance of midgut microbiotas (KEY = OTUs) of worker bees overwintered in an indoor climate controlled facility: "Cold wintering", and an outdoor apiary in Southern Arizona, USA: "Warm wintering". Each vertical bar is the midgut microbiota of a single bee from a different colony. Outlined in bold, the core five hindgut bacteria declined significantly in the warm outdoor environment, but increased significantly in the cold indoor environment. Significantly larger midgut microbiotas are associated with Enterobacteriacae (RED) and Gilliamella spp. (GFP green). See Table S2 and results for more statistical details. 

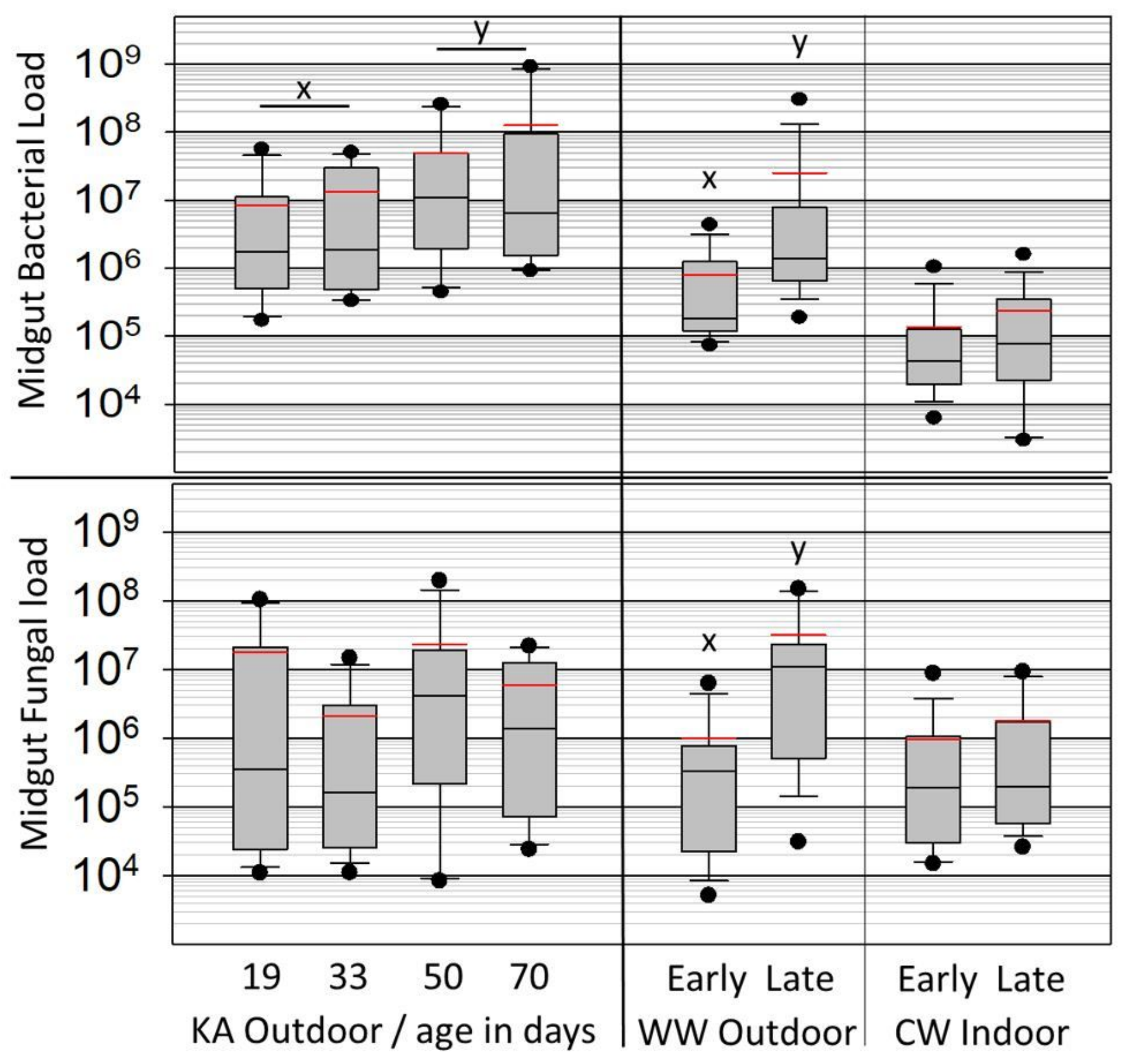

Figure 6

Bacterial and fungal load in the worker midgut of overwintering honey bees. The $y$-axis represents $16 \mathrm{~S}$ rRNA copy number (bacterial load) and 18S rRNA copy number (fungal load). To provide reference, we repeat midgut microbial loads (from Fig. 4) of known age bee midguts. The WW samples differed significantly from early to late winter for both fungal load (W32 $=42, p=0.0008)$ and bacterial load (W30 $=43, p=0.003$ ). See methods for more sampling details. Grey boxes contain $75 \%$ of the variation, whiskers contain $90 \%$, and the dots are outliers. The horizontal red bar is the mean and black is the median. Bacterial load corresponds to microbiotas in Figure $3(\mathrm{KA})$ and Figure 5 (WW/CW). 


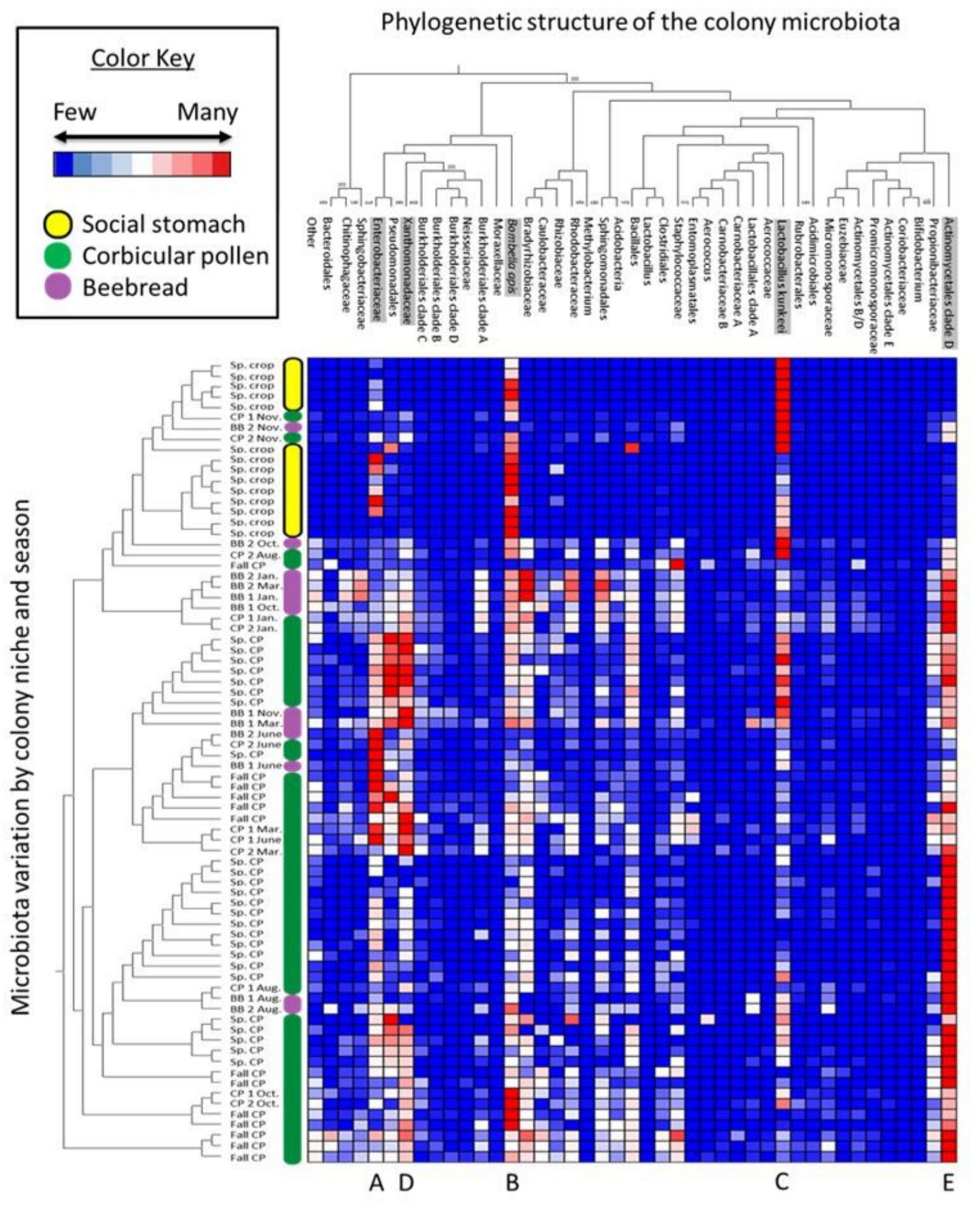

Figure 7

Heatmap depicting a portion of the colony microbiota by niche. Data are 16S rRNA gene sequences of corbicular pollen (CP), beebread BB and the crop in Spring (Sp.) and Fall $[28,30]$. Representation based on variance-adjusted weighted pairwise Unifrac distances among all sequences. The social stomach (foregut or crop), populated primarily by Enterobacteriaceae (A), Bombella apis (B) and Lactobacillus kunkeei (C), separates the mouthparts and midgut, and serves a social hygienic function suppressing 
disease transmission and establishment. Note the distribution and abundance of other OTU's associated with mouthparts and midguts in the present study, including Xanthomonadales (D) and Actinomycetales (E) highlighted in grey.

\section{Supplementary Files}

This is a list of supplementary files associated with this preprint. Click to download.

- TableS1.Hostmicrobialcorrelations.xlsx

- TableS2.Microbiotaabundanceandanalysis.xlsx

- TableS3.NosemaqPCR.xlsx

- TableS4.Immunegeneexpression.xlsx 